\title{
Organic functionalized carbon nanostructures for solar energy conversion
}

\author{
Luca Lazzarin ${ }^{1}$, Mariacecilia Pasini ${ }^{2 *}$ and Enzo Menna ${ }^{1,3 *}$
}

1 Department of Chemical Sciences \& INSTM, University of Padua, Via Marzolo 1, 35131 Padova; luca.lazzarin@phd.unipd.it (L.L.); enzo.menna@unipd.it (E.M.)

2 Institute of Chemical Sciences and Technologies "G. Natta"-SCITEC, National Research Council, CNRSCITEC, via Corti 12, 20133 Milan, Italy; mariacecilia.pasini@scitec.cnr.it

3 Interdepartmental Centre Giorgio Levi Cases for Energy Economics and Technology, University of Padua, Padova, Italy

* Correspondence: enzo.menna@unipd.it (E.M.); mariacecilia.pasini@scitec.cnr.it (M.P.)

\begin{abstract}
This review proposes an overview on the use of organic functionalized carbon nanostructures (CNSs) into solar energy conversion schemes. Our attention has focused in particular on the contribution given by organic chemistry to the development of new hybrid materials that find application in dye sensitized solar cells (DSSC), organic photovoltaics (OPV), perovskite solar cells (PSC) and also in photocatalytic fuel production, focusing in particular on the most recent literature. The request for new materials able to accompany the green energy transition that are abundant, low cost, with low toxicity, from renewable sources has further increased the interest in CNSs that meet all these requirements. The inclusion of an organic molecule, thanks to both covalent and non-covalent interactions, into a CNS, leads to the development of a completely new hybrid material able of combining and improving the properties of both starting materials. Besides the numerical data, which unequivocally state the positive effect of the new hybrid material, we hope that these examples can be inspiring for further research in the field of photoactive materials from an organic point of view.
\end{abstract}

Keywords: Carbon nanotubes, graphene, reduced graphene oxide, graphene quantum dots, organic functionalization, dye, organic photovoltaics, dye sensitized solar cells, perovskite solar cells, photocatalytic hydrogen evolution

\section{Introduction}

Research on organic photovoltaics (OPV) exploded at the beginning of the millennium thanks to the use of fullerene derivatives as electron acceptors, coupled with conjugated polymers as donor materials [1-3]. Development of OPV actually followed the discovery of fullerenes, and in particular it took off as soon as the first efficient functionalization approaches became available.

Since then, the evolution of the field of non-conventional or third-generation photovoltaics have introduced new families of devices, such as dye sensitized solar cells (DSSC), perovskite solar cells (PSC) and photocatalytic cells, based on different active materials, but sometimes also reinventing the role of fullerenes [4]. At the same time, new carbon allotropes, collectively named carbon nanostructures (CNS), have been explored as components with the aim to improve energy conversion efficiency or stability of devices [513].

Indeed, CNS superior properties, like metallic or semiconducting electronic behavior, thermal conductivity and surface area, can contribute to the enhancement of solar conversion into electricity or into production of fuels through photocatalysis. Although many examples based on pristine CNSs are reported, the present review is focused on the contribution of organic chemistry in this field, as reported in the most recent literature. In fact, organic moieties can modify CNSs to provide or modify fundamental properties for 
the development of energy conversion applications, such as light absorption, electron transfer, charge transport, solubility and interaction with a polymer matrix [14].

\section{Chemistry of Carbon Nanostructures}

The family of CNSs includes carbon nanotubes (CNT), either single or multi walled (SWCNT and MWCNT respectively), graphene-based materials (GBM), carbon dots and graphene quantum dots (GQD). The most common GBMs, in turn, are graphene, graphene oxide (GO) and reduced graphene oxide (RGO), although there is no sharp distinction among them. In fact, a continuous variation of structural features is found in GBMs, involving the density of oxygenated groups (O/C atomic ratio), lateral size of sheets and number of layers [15].

Covalent and non-covalent functionalization strategies have different advantages and drawbacks. While covalent chemistry is based on a stable linkage, providing good solubility and ensuring a closer proximity of the active moiety to the CNS, thus enabling efficient electron transfer processes, supramolecular or non-covalent approaches avoid the need of complex reactions and purifications involving CNS suspensions. In fact, once the proper molecular structure is obtained through conventional synthesis, a simple mixing with the suspended CNS is required. Moreover, covalent chemistry involves the introduction of $\mathrm{sp}^{3}$ defects in the $\mathrm{sp}^{2}$ lattice of CNTs and graphene that can often have a negative impact on the electrical properties of the material, while non-covalent strategies have been developed that allow to improve the CNSs processability without degrading electronic features [16].

Some covalent strategies are based on carboxylic groups or other oxidized moieties, others relay on specific reactions taking place on the $\mathrm{sp}^{2}$ carbon lattice.

Among the latter family, the 1,3 dipolar cycloaddition of azomethine ylides, one of the most widely used reaction of fullerenes [17], was adapted for the functionalization of CNTs [18] and graphene [19] and it is known as Prato reaction. The reactive azomethine ylide is usually obtained in situ through decarboxylation of an immonium salt, derived from the condensation of an $\alpha$-aminoacid with an aldehyde. Cycloaddition of the ylide to a double bond of the nanostructure affords a pyrrolidine ring fused to the CNS. The commercial availability of a wide range of carbonyl and aminoacid precursors and the possibility to obtain more through simple chemical transformations makes this reaction an extremely versatile functionalization tool. In fact, a proper choice of precursors allows to introduce one or more desired residues on the derivative, as substituents on the different positions of the pyrrolidine ring.

Diazonium chemistry provides an efficient mean for the functionalization of CNTs and GBMs, through the so called Tour reaction, after the name of the researcher who first introduced it [20]. The diazonium salt, either previously isolated or generated in situ, starting from an aniline precursor, undergoes reductive dissociation with loss of $\mathrm{N}_{2}$ and formation of an aryl radical that reacts with $\mathrm{C}=\mathrm{C}$ double bonds of the CNS. The reaction is quite fast and can afford derivatives densely decorated with aryl moieties or even with branched oligomeric structures when pushing reaction conditions [21]. In general, starting with an aniline with the desired moiety in position 4 , it is possible to obtain a CNS decorated with the corresponding phenyl derivative.

As first proposed by Smalley and coworkers back in 1998 [22], carboxylic groups can be formed on CNTs through oxidation and then used to form amide or ester bonds with molecules bearing amine or alcohol groups respectively. Different oxidation approaches have been proposed, although the most commonly used is based on treatments with strong acid mixtures such as concentrated $\mathrm{HNO}_{3} / \mathrm{H}_{2} \mathrm{SO}_{4}$. As with usual organic synthesis, amidation can follow different activation strategies, such as the formation of acyl halide intermediates or the use of carbodiimide coupling agents. The same approach can be adapted to all CNSs, taking in account that in the case of GO carboxylic groups are already present in the structure.

Non-covalent functionalization takes advantage of the $\mathrm{sp}^{2}$ carbon surface of CNSs to establish hydrophobic interactions in general, but more specifically $\pi-\pi$ interactions with 
large aromatic structures [23] including a number of pyrene derivatives [24-26], but also conjugated polymers $[27,28]$ and porphyrins [29].

A peculiar non covalent approach, in the case of CNTs, consists of the encapsulation of molecules inside the tubes to afford the so-called peapods, first introduced by Luzzi with fullerenes [30]. A typical encapsulation procedure is based on the diffusion of molecules in the vapor phase at high temperature and low pressure or from solution or even by means of supercritical carbon dioxide [31]. The approach was more recently extended also to a range of photoactive organic molecules [32].

Besides common experimental techniques for the detection of covalent bonds, like FT-IR and NMR (that in the case of CNS derivatives hardly find application), typical characterizations of materials can effectively provide evidence of CNS functionalization. Thermogravimetric analysis (TGA), in particular, allows to quantify the functionalization degree (FD), defined as fraction of CNS carbon atoms that are functionalized with respect to the total carbon atoms, by comparing the weight loss due to the organic fraction with that of the nanostructure (occurring at higher temperatures) [33].

On the other hand, experimental evidence of non-covalent interactions for aromatic molecules and quantification of association constants can be provided by fluorescence measurements [34,35].

\section{Dye Sensitized Solar Cells}

Since the first discovery of a dye-sensitized solar cell (DSSC) by Grätzel and O'Regan [36], this technology has drawn the interest of scientists from all over the world. Thanks to a new cost-effective approach to the energy conversion, this scalable, versatile device finds its application in a different area in respect to the usual silicon-based cell. While thorough and exhaustive descriptions of the generic aspects of DSSC device and its specific architecture can be found in the literature [36-38], we can briefly recall the basic concepts here. In general, a molecular sensitizer (dye), adsorbed on an inorganic semiconductor $\left(\mathrm{TiO}_{2}\right)$ is excited by solar light, giving rise to a subsequent electron injection from the dye to titania. The oxidized sensitizer is regenerated by a redox mediator (usually a $\mathrm{I}_{3} / \mathrm{I}$ redox couple) dissolved in an electrolyte.

Percolation through $\mathrm{TiO}_{2}$ and then to the anode feeds electron circulation in the external circuit, ending with the injection from the cathode to redox mediator in the electrolyte, thus closing the circuit.

In an effort to minimize the cost and the environmental impact, recent advances are reported [39] regarding the substitution of the Ruthenium-based dyes with metal-free organic molecules and the principle in the design of this new class of sensitizers [40]. This review starts from the metal-free approach but proposes a further insight taking into account hybrid materials which spring from the co-use of CNS and organic moieties as photoactive element.

There are mainly three unwanted processes:

- Back-electron-transfer, when the photo-injected electron interacts with the oxidized state of the sensitizer or the oxidized state of redox couple.

- Excited state deactivation consisting of radiative and/or non-radiative paths involving the dye.

In order to minimize the detrimental effect on the overall performance, it is necessary to elaborate suitable improvements regarding the architecture of the cell itself and the materials used. Several strategies have been developed to optimize the overall efficiency, including the use of carbon-based materials, which have been shown so far promising effects.

The very first successful inclusion of a CNS in a DSSC has paved the way to a new concept in the design of the solar cell. At first the synergistic use of graphene-materials regarded mainly the construction of transparent electrodes, semiconducting layers and counter-electrodes, as already exhaustively reported [5] [41], and the specific use of carbon nanotubes in the construction of DSSCs has been studied and reviewed as well [42]. However, the only use of carbon nanostructure reported before 2010 was as a pristine sensitizer 
of the semiconductor, in the form of quantum-dots [43]. The idea behind this application lies in the high electron mobility and in the strong and broad absorption profile of pristine graphene, that is able to absorb around $2.3 \%$ of light for each single carbon layer [44]. Unfortunately, the performance generated by cells with pristine graphene was quite low $(\eta=0.06 \%)$, but since then several improvements have been introduced, giving rise to a new class of hybrid materials.

For instance, in a recent publication Gatti et al., proposed a new hybrid dyad DSSC photosensitizer using RGO and a donor- $\pi$-acceptor system [45]. The organic unit attached was triphenylamine (D)-thiophene $(\pi)$-cyan acrylic acid (A), covalently bound thanks to the Tour reaction. The molecule shows a relevant absorption of visible light due to the extended $\pi$-conjugation which allows an efficient push-pull effect of photoexcited charges throughout the molecular backbone.

A schematic representation is reported in Figure 1.

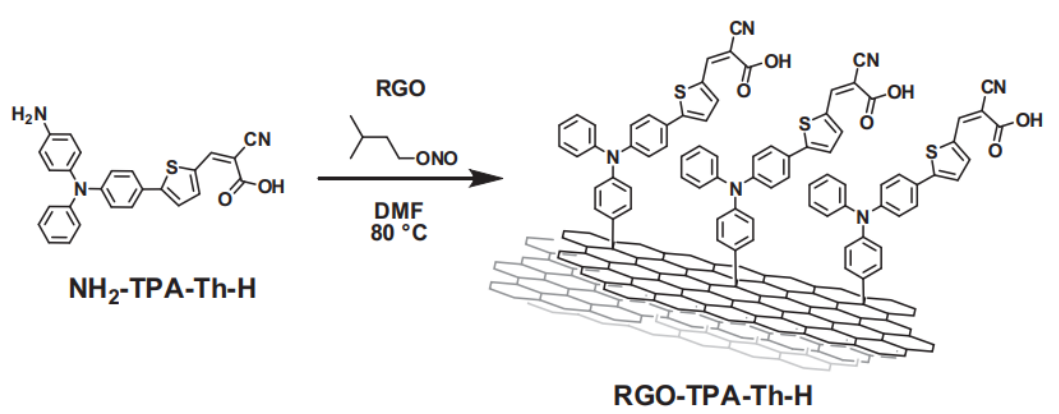

Figure 1. Functionalization of RGO with the donor- $\pi$-acceptor system to furnish the new hybrid species. Reproduced from Ref. [45] with the permission of Elsevier.

Covalent binding was demonstrated by bathochromic shift in comparison with the free dye (TPA-Th-H): the $\pi-\pi^{*}$ transition shifts from 303 to $308 \mathrm{~nm}$, and the internal charge transfer ICT peak from 409 to $411 \mathrm{~nm}$, accordingly to other chromophores reported in the literature [46]. A further proof can be found in the Raman spectrum. The different ID/IG ratio in comparison with pristine RGO demonstrates that the RGO defects are modified by means of the covalently introduced organic moieties. The performance of the cell was not high, which can be attributed to a low loading of the TPA-Th-H unit, but harsh desorption experiments $\left(1 \mathrm{M} \mathrm{NaOH}\right.$ in $\mathrm{DMF}$ at $70^{\circ} \mathrm{C}$ for 7 days) highlighted the chemical stability of the new hybrid system.

The photo-physics of a similar system is reported [47], allowing few interesting considerations about the role of the RGO in a photoactive push-pull system. The hybrid under examination is shown in Figure 2.
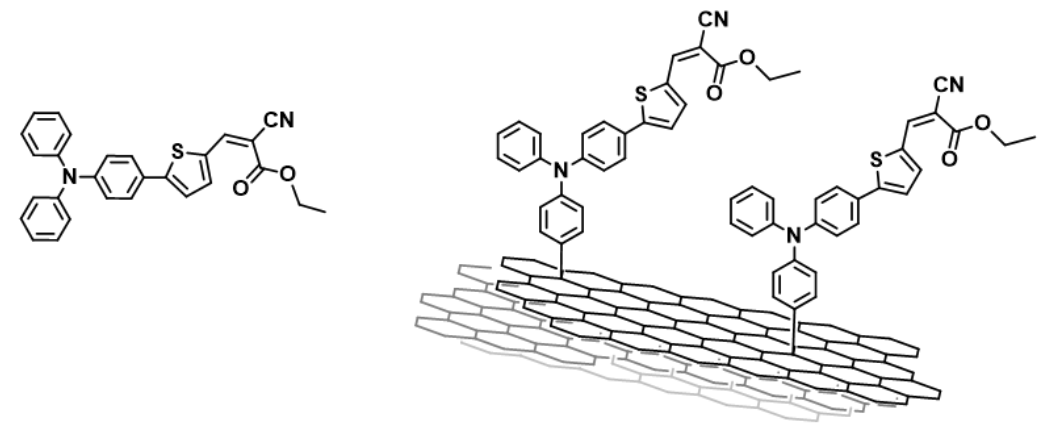

TPA-Et

RGO-TPA-Et

Figure 2. Structure of the reference free dye TPA-Et (left) and hybrid material RGO-TPA-Et (right) discussed in Ref. [47].

Even in this case, the bathochromic shift of $3 \mathrm{~nm}$ between the free dye $(406 \mathrm{~nm})$ and the dyad $(409 \mathrm{~nm})$ testifies the covalent bound. 
Steady state photoluminescence (in particular in the region of 500-700 nm) measurements were performed, showing an evident quenching of the emission of methyl-2-cyano3-(4-(diphenylamino)phenyl)acrylate (TPA-Et) when attached to RGO. Time-resolved photoluminescence experiments confirmed the faster photoluminescence decay of the hybrid in comparison with the free TPA-Et. These data therefore suggest that the photoinduced charge separation is rapidly quenched in presence of RGO. It then is highlighted the high mobility of electrons between the $\pi$-system and the inorganic substrate. Additionally, electron paramagnetic resonance (EPR) measurements of the hybrid system and the reference both attached to $\mathrm{TiO}_{2}$, demonstrate unequivocally that the electron transfer from TPA-Et to the semiconductor takes place, even in the presence of RGO. It is therefore legitimate to assume that the RGO acts like an electron reservoir, being able to efficiently reduce the oxidized state of TPA-Et and consequently helping the regeneration of the sensitizer. Moreover, given the tendency of TPA-Et radical cation to dimerize, the presence of a substrate capable of the immobilization of the dye should be beneficial for the longterm stability of the cell under operating conditions. In addition, the steric hindrance of a bulky substrate such as the RGO grants a lesser $\pi$-stacking which is a common problem that affects the photovoltaic performance [48].

A different approach to the functionalization of MWCNTs concerns the formation of a dyad thanks to the introduction of reactive moieties on the surface of the CNS. For instance, a metallo-octacarboxyphthalocyanines (MOCPc) has been reported as a hybridsensitizer in a DSSC [49]. Metallophthalocyanines (MPc) are complexes containing nontransition metals, such as $\mathrm{Zn}$ or $\mathrm{Si}(\mathrm{OH})_{2}$, placed in a wide $\pi$-system. These $18 \pi$-electrons aromatic porphyrins are limited as photoactive element because of MPc dye aggregation, electron recombination with oxidized dye molecules and a lack of electronic connectivity with the surface of the semiconductor. In order to overcome these limitations, a covalent hybrid with MWCNT has been synthesized, whose spectroscopic absorption is reported in Figure 3.

(a)

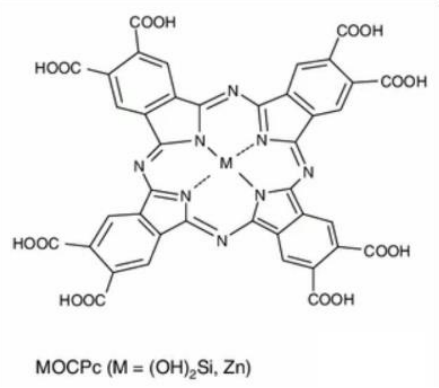

(b)

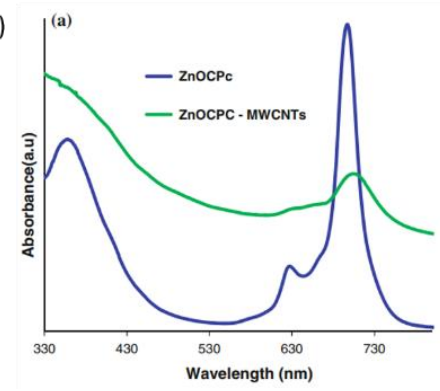

Figure 3. Structure of the MPc (a), and absorbance behavior of the pristine $\mathrm{ZnPc}$ and its hybrid (b). Reproduced from Ref. [49] with the permission of Springer Nature.

The spectrum collected in DMF shows two absorptions in the visible range at 680$700 \mathrm{~nm}$ due to the monomeric species and at $620 \mathrm{~nm}$ due to the dimeric species. The introduction of the CNTs causes a red shift of the main peak, in accordance with the attachment of an electron-withdrawing group such as the amine-functionalized CNT.

An interesting approach has been adopted in this work, especially in comparison with the others previously reported, because the MWCNT was pre-treated and then, after the attachment of reactive groups, it was covalently bound to the MPc as shown in the following scheme. 


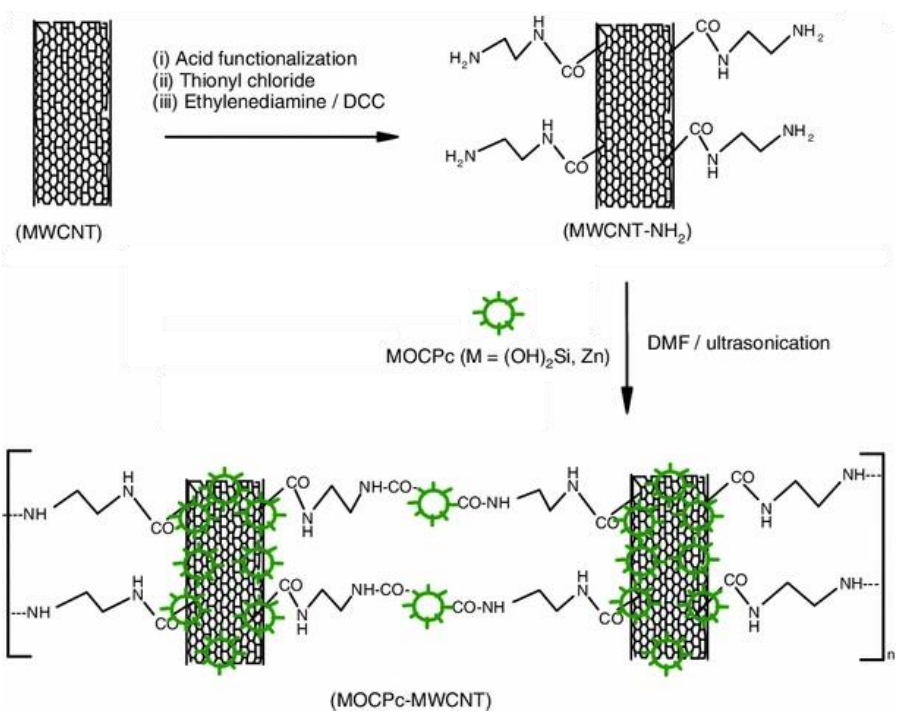

Figure 4. Synthetic route for the MOCPc- MWCNT hybrid. Reproduced from Ref. [49] with the permission of Springer Nature.

The so-synthesized hybrid was further studied under the photoelectrochemical point of view in a typical DSSC. We can discuss the effect of the introduction of the CNS referring to photo-electrochemical impedance spectroscopic studies and photo-chronoamperometric studies. The latter analysis shows a rectangular shape for the free sensitizer in response of the on/off light, and it can be attributed to an intimate contact between the electrolyte and the MOCPc. The same conclusion can be made for the hybrid, but, in addition, we want to highlight the enhanced photocurrent after the introduction of the MWCNT, equal to an improvement of the $36 \%$. The positive effect on the photocurrent could be a consequence of a better light scattering by the MWCNTs in proximity of the $\mathrm{TiO}_{2} /$ electrolyte interface [50]. The electro-impedance measurements are an effective tool for the investigation of the electro-transport and recombination mechanisms which take place in a DSSC. The Nyquist plots show a three times smaller semicircle for the MWCNT$\mathrm{MPc}$ and it can be clearly related to a significant reduction in the charge transfer resistance at the TiO2/MPc-dye/electrolyte interface. Thanks to the relatively high conductivity characteristic of the MWCNTs, the photo-promoted electrons can rapidly diffuse into the embedded CNS resulting in a lower overall resistance and a higher photocurrent density. Once again, the synergy between organic chemistry and chemistry of materials leads to a better hybrid which overwhelms the individual elements of itself.

Another similar complex consisting of a NIR absorbing azulenocyanine and few layers of graphene has been reported [51]. In this case the wide aromatic core of the azulenocyanine promotes the exfoliation of graphene thanks to effective $\pi-\pi$ interactions with the basal plane of graphene. A schematic representation is shown in Figure 5.
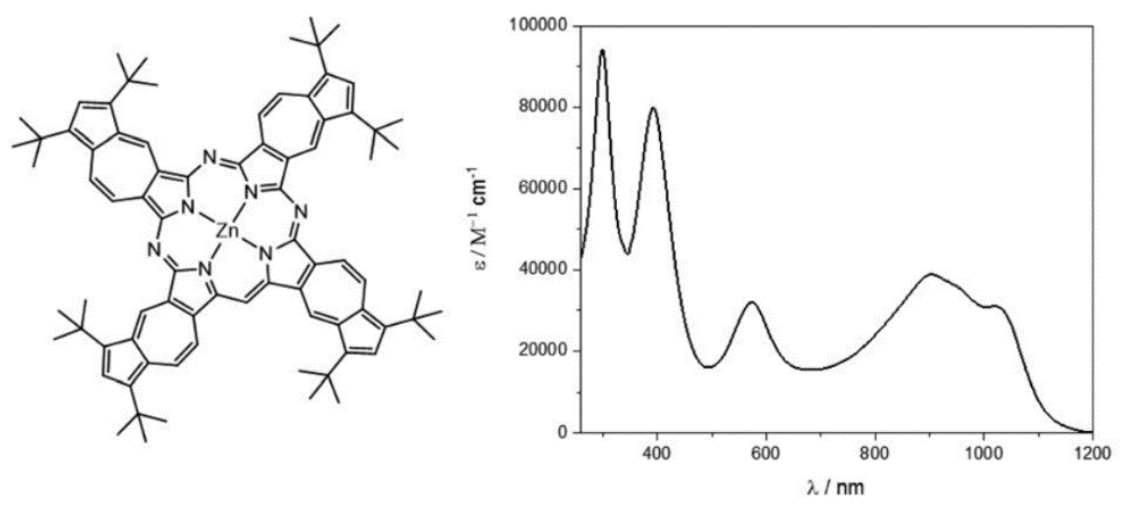
Figure 5. Azulenocyanine $\pi$-extended system and absorption spectrum. Reproduced from Ref. [51] with the permission of the Royal Society of Chemistry.

The UV-Vis-NIR spectrum shows the characteristic absorbance of the molecule under examination. Focusing on the visible range, two main peaks are dominating the spectrum around 400 and $580 \mathrm{~nm}$. The former resembles the Soret band absorption of phthalocyanine, the latter the Q-band. Additionally, a wide absorption is present in the NIR region, ranging from 800 to $1100 \mathrm{~nm}$. These spectroscopic features make the complex under analysis a suitable candidate for a DSSC application. Electrochemical measurements, which points out the better behaviour as electron-donor of the azulenocyanine, in addition to pump probe experiments highlight the electron transfer from the $\pi$-system to graphene upon photoexcitation. The concomitance of these two features makes the sensitizer a promising candidate for its use in DSSC. Both the free dye and the hybrid system were used as sensitizers in a DSSC but unfortunately, it turned out that voltage and current density are low. That could be ascribed mainly to two factors. Firstly, the lack of carboxylic acid which allows a strong binding to $\mathrm{TiO}_{2}$. Secondly, the driving force promoting the photo-injection of the electron is very low due to energetic disposition of the lowest unoccupied molecular orbital (LUMO) in comparison to the lower edge of the conduction band. Nonetheless, it was proven that the hybrid system generates better performance than the free azulenocyanine.

Another peculiar system is reported by Kaur et al. [52], and it regards the immobilization of a metal organic framework (MOF) on a graphene sheet. To begin with, MOFs are structures hierarchically organized that mimic the structure of natural entities such as chloroplasts [53]. They can be synthesized from different organic linkers and metal centers, but a common feature is the high surface area, which efficiently absorbs incident light and makes them suitable for energy conversion system. The idea behind the use as a sensitizer in DSSCs lies in the ability of these structures to absorb light and photoinject electrons in $\mathrm{TiO}_{2}$ films, as proven in other works [54]. The structure and absorption spectrum of the $\mathrm{MOF}$ under examination, based on a $\mathrm{EuO} 9$ polyhedra, is reported in Figure 6.

(a)

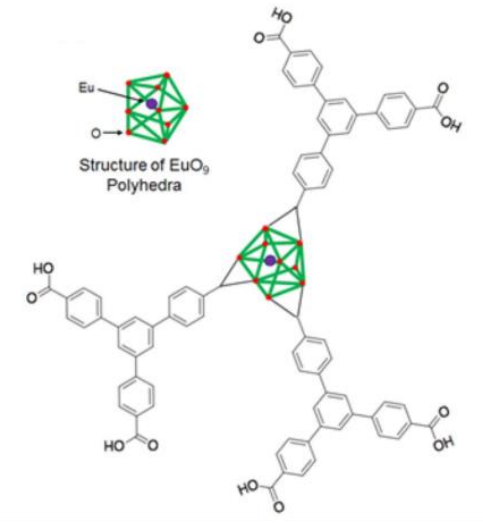

(b)

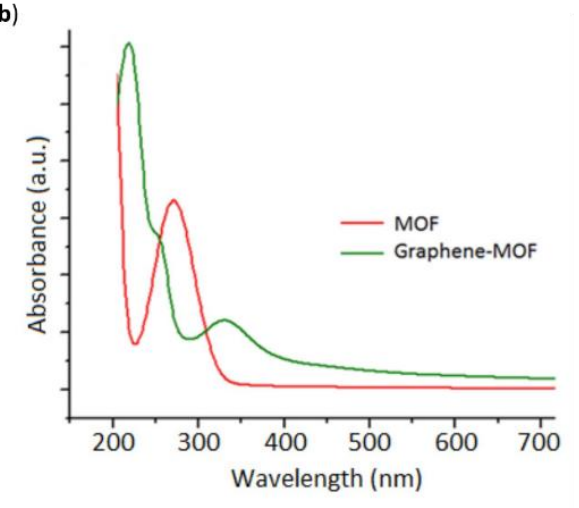

Figure 6. Structure of Eu-MOF (a). Absorbance profile (b) of the pristine MOF and the hybrid MOF-graphene. Reproduced from Ref. [52] with the permission of Elsevier.

The spectrum underlines the strong UV absorbance around $260 \mathrm{~nm}$ of the MOF due to the contribution of the ligands. When combined with graphene instead, a new peak around $250 \mathrm{~nm}$ appears which can be attributed to $\eta-\pi^{*}$ transition of the C-O bond [55]. The absorbance spectrum, concurrently with FT-IR and Raman measurements, demonstrates the successful inclusion of the MOF in a graphene sheet thanks to a simple electrochemical deposition. In fact, the structure remains intact after the electro-deposition and the interaction binding the Eu-MOF to graphene can be identified in the $\pi-\pi$ stacking. The concurrent use of graphene can make up for the characteristic insulating nature of the MOF-Eu (conductance of the order of $10^{-12} \mathrm{~S} \mathrm{~cm}^{-1}$ ), in fact the novel material shows an efficient electron collection and an improved conductance $\left(300 \mathrm{mS} \mathrm{cm}^{-1}\right)$. Specifically, even 
if MOF can act as a photoactive material, it cannot conduct electricity. However, MOFgraphene composite has proven to efficiently inject electrons in the conduction band of $\mathrm{TiO}_{2}$. In conclusion, a thin film graphene-MOF was proven in a lab-scale DSSC device, reaching a power conversion efficiency (PCE) of $2.2 \%$ which is by far better than the previously reported MOF-based DSSC [56].

Moving towards an eco-friendly approach, the use of natural dyes obtainable directly from natural sources has spread over the past years [57]. This trend perfectly suits the desired low cost and environmental low impact feature of DSSC technology and, in particular, a specific attention has been focused on totally renewable sensitizers coming from seaweeds and algae [58-60]. In this regard, we point out a hybrid system stemming from the co-use of GQD and green and red algae [61]. Both algae were treated with a simple extraction method, and the resulting dye was a mixture of the photoactive components present in the seaweed. The red alga, named Gracilaria, shows an absorption characteristic of Phycobilins, instead the green one, known as Ulva, is characterized by spectroscopic features of the Chlorophyll family. Both were tested as photoactive elements, as a pristine molecule and as a hybrid material, in a conventional DSSC set-up. We report the absorption spectrum of the sensitizers and their respective hybrids in Figure 7.

(a)

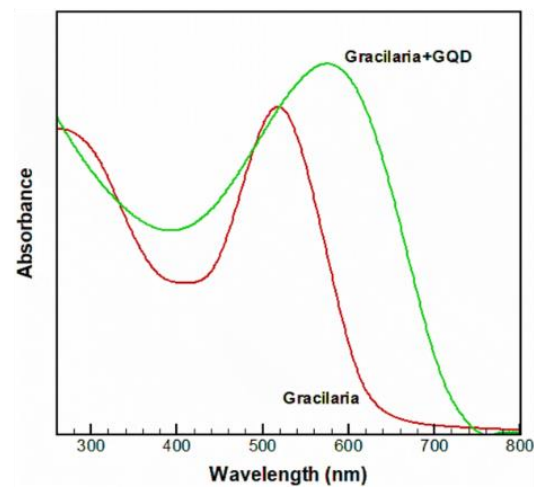

(b)

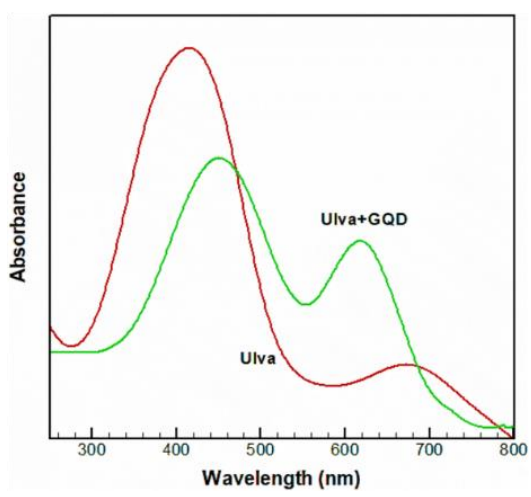

Figure 7. Absorbance spectrum in Ethanol of Gracilaria and its hybrid material (a) as well as Ulva (b). Reproduced from Ref. [61] with the permission of Springer.

Two main absorptions in the near visible region are present in Figure 7 for the dyes extracted from Gracilaria and Ulva, respectively at 530 and $420 \mathrm{~nm}$. The visible light absorption can be attributed to the excitation from $\sigma$ and $\pi$ orbital to the lowest unoccupied molecular orbital. Since Gracilaria is characterized by a broader absorption in the visible region, it is expected to be a better chromophore in its energy conversion application. Subsequently, the introduction of graphene quantum dots can be estimated referring to the absorption spectrum. In both cases, there is a widening and a red-shift of the peak that has been reported in the literature as a direct effect between the nanostructure and the dye [62]. The introduction of GQDs is thought to alter the disposition of the HOMO-LUMO orbitals, consequently resulting in a faster electron extraction which has a beneficial impact in the overall performance of the cell [63]. This statement is proved in this work as well: the efficiency of DSSC using pure Gracilaria rises from $0.52 \%$ to $0.94 \%$ after the introduction of GQDs. In a similar manner, in the case of Ulva, it is improved from $0.39 \%$ to $0.81 \%$ following the co-use of the CNS. Photoluminescence measurements show a severe quenching after the addition of GQDs, and as previously reported and discussed, it could be a proof of an intimate contact in terms of electron exchange. The radiative path from the excited state to the ground level is inhibited by the presence of the CNS, meaning a reduction in electron-hole recombination under the photo-conversion point of view.

Another useful application of a CNS, reported by Sireesha et al. [64], regards the synthesis of a hybrid nanocomposite and its use as photoanode in a DSSC. The role of the thin film is related to the hole and electron conductivity. To start with, we can focus on the nature of the hybrid under analysis, which basically is a carboxylic acid-functionalized multi-walled carbon nanotubes-polyindole/ $\mathrm{Ti}_{2} \mathrm{O}_{3}$ nanocomposite (f-MWCNTs-PIN/ 
$\mathrm{Ti}_{2} \mathrm{O}_{3}$ ). The route that leads to such new materials starts with the functionalization of MWCNTs by the means of a strong oxidizing solution made of $\mathrm{HNO}_{3} / \mathrm{H}_{2} \mathrm{SO}_{4}$. The newly introduced carboxylic acid functionalities on the CNS allows the reaction with indole. A schematic illustration is reported in Figure 8.
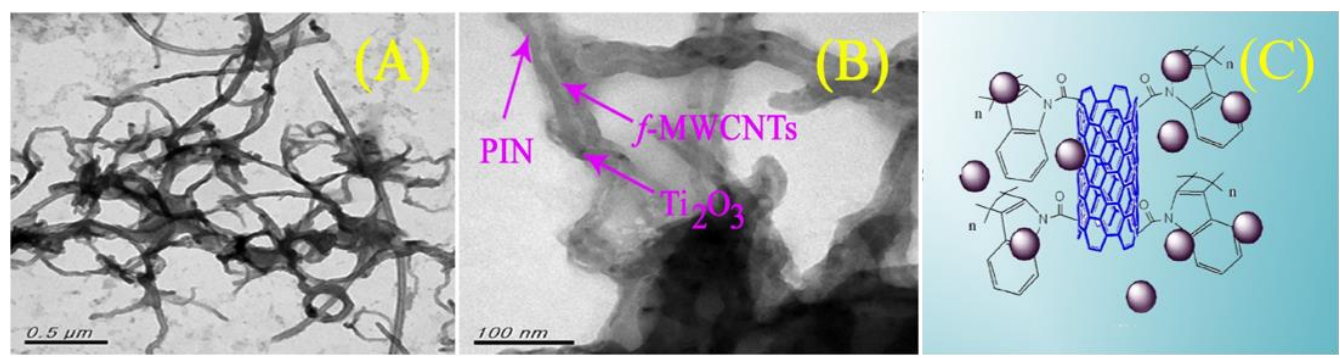

Figure 8. TEM images of f-MWCNTs-PIN/Ti2O3 nanocomposite (A), its detail (B), and illustration of the nanocomposite hybrid f-MWCNTs-PIN/Ti2O3/TiO2 (C). Reproduced from Ref. [64] with the permission of Elsevier.

As it appears from the image, the smooth surface of the f-MWCNT does not allow the deposition of the indole, and consequently, the growth of poli-indole PIN starts preferentially on the surface of $\mathrm{Ti}_{2} \mathrm{O}_{3}$ due to the high surface area and the different chemical activity. The so-synthesized hybrid material can be rationalized into a wire of $\mathrm{Ti}_{2} \mathrm{O}_{3}$ nanoparticles functionalized with poly-indole and interconnected by the carbon nanotubes. The enhanced photocatalytic activity can be seen from its application in a DSSC sensitized with Di-tetrabutylammonium cis-bis(isothiocyanato)bis(2,2'-bipyridyl-4,4'-dicarboxylato)ruthenium(II) (known as N719) dye: the experimental results show that the photovoltaic performance of the DSSCs is improved from $8.15 \%$ to $8.65 \%$ in comparison to a reference photoanode.

So far, the selected literature works clearly demonstrate that the inclusion of an organic molecule, thank to both covalent and non-covalent interaction, into a carbon nanostructure, leads to the formation of a completely new material which can be characterize by better spectroscopic absorbance, improved conductivity and/or enhanced photocurrent density. Besides the numerical data, which unequivocally state the positive effect of the new material, we hope that these examples can be inspiring for further research in the field of photoactive materials from an organic point of view.

\section{Perovskite and Other Hybrid and Organic Photovoltaics}

Organic and hybrid photovoltaics, based on sandwiching an active layer, between 2 electrodes capable of generating a charge once photoexcited, are experiencing ever greater development in recent years thanks to the increasing efficiency of the devices. $[65,66]$ For a detailed description of the operating principles, see the reviews $[67,68]$.

Considerable progress has been achieved both by developing new materials for the active layers, see for example non-fullerenic acceptor systems [69] in organic photovoltaics (OPV) or the use of perovskites in hybrid cells (PSC) [70], but also by engineering the interfaces with the electrodes using layers that can act as HTM (hole transporting materials) or ETM (electron transporting materials) [71-73].

Thanks to their versatility, carbon-based nanostructured materials can be used both as active materials and as charge regulating layers both in OPV cells and PSC cells [74-76]. The major limit of CNSs based materials is their poor solubility and consequently the poor optical and morphological quality of their films. To overcome this problem, both a covalent and a non-covalent functionalization approach of CNSs have been proposed.

Considering covalent functionalization in 2015 Salice et al. [77] proposed CNTs derivatization by Tour reaction. In particular starting from the consideration that thienyl group increase the interaction between CNT and the P3HT used as active layer in OPV they synthetized the 4-(thien-2-yl)-aniline that was reacted with isopentylnitrite in 1-cy- 
clohexyl-2-pyrrolidone for the in-situ generation of the diazonium salt used for the derivatization of CNTs. SWNCTs (Figure 9) produced by the HiPco $[78,79]$ process were functionalized by simple addition of the diazonium salt of the aniline derivative with two different approaches one based on the traditional reactions in a flask at $80^{\circ} \mathrm{C}$ for $4 \mathrm{~h}$ and the other based on flow reactors, by setting a flow rate of $8.0 \mathrm{~mL} / \mathrm{h}$ and a temperature of 80 ${ }^{\circ} \mathrm{C}$, since they offer good productivity, increased safety and control on the reaction parameters with respect to traditional synthetic procedures [80].

The functionalized materials at the end of the addition reaction were precipitated by centrifugation after addition of methanol. For the preparation of solution-processable SWCNT/P3HT blends, the soluble fraction of the SWCNT-PhTh derivative was isolated by extraction with chlorobenzene sonicated and the supernatant was collected after the precipitation of less soluble material.

Importantly the study of different P3HT:CNTs heterojunctions evidenced that an excessive modification of the CNTs surface, due to the high number of carbon atoms converted from $\mathrm{sp}_{2}$ to $\mathrm{sp}_{3}$ after the functionalization, resulted in the decreasing of the electronic and thermal properties of pristine CNTs. Moreover, an uncontrolled functionalization shields the surface of CNTs thus preventing the interaction with P3HT. The use of flow methods for CNTs functionalization has allowed to obtain derivatives with a good compromise between processability and retention of the SWCNT properties required for an electronic interaction with P3HT.

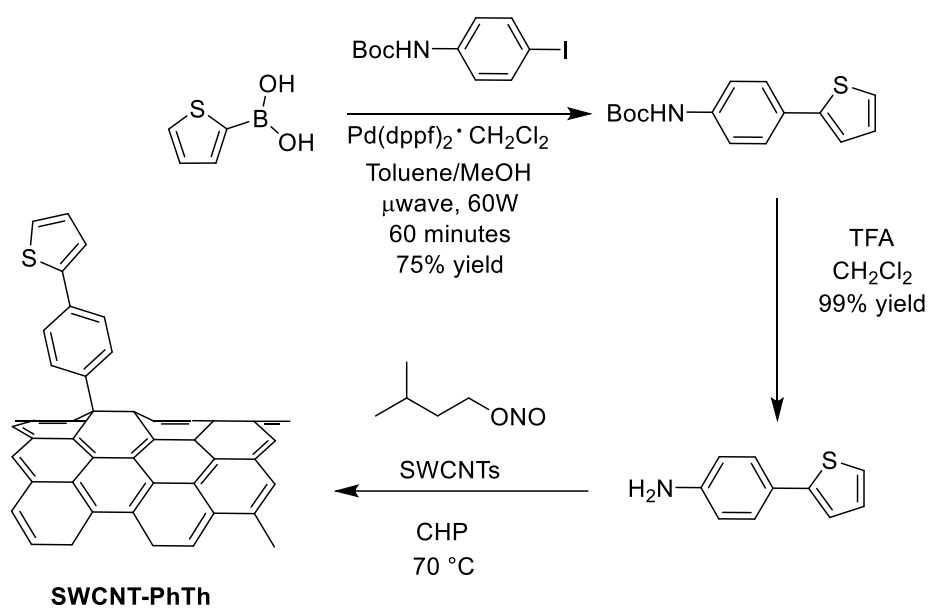

Figure 9. Functionalization of SWCNTs via the addition of the diazonium salt of 4-(thien-2-yl)aniline. Reproduced from Ref. [77] with the permission of The Royal Society of Chemistry

The covalent functionalization via Tour reaction of SWCNTs and RGO has been proposed $[81,82]$ for the development of HTM in PSCs. Literature data indicates that CNSs have a double ability to increase both efficiencies and stabilities of PSC devices. In fact CNSs "shield" the perovskite film from atmospheric moisture adsorption and thermal degradation $[75,83]$, and at the same time they facilitate hole extraction from the perovskite layer, [84,85] if compared to usual HTMs as Spiro-OMeTAD [86].

In this framework SWCNTs and RGO, covalently functionalized with p-methoxyphenyl substituents (to obtain derivatives SWCNT-PhOMe and RGOPhOMe respectively) embedded in P3HT HTMs have been proposed [81]. The functionalization proceeds through the in-situ generation of the diazonium salt of $\mathrm{p}$-methoxyaniline in the presence of isopentylnitrite, using 1-cyclohexyl-2-pyrrolidone (CHP) as the solvent. The relative amounts of reactants together with the reaction times have been regulated to avoid an excessive functionalization of the CNSs derivatives preserving their electronic properties.

The electronic structure of the pristine SWCNTs was preserved as confirmed in absorption spectra and FD of 5\% for SWCNT-PhOMe and 3.4\% for RGOPhOMe has been estimated from TGA.

Ultrasonication followed by centrifugation steps has been reported to blend SWCNTPhOMe or RGO-PhOMe in P3HT matrix (see Figure 10). The centrifugation steps allowed 
to remove the insoluble residues, and homogeneous blends of functionalized CNSs and P3HT in chlorobenzene, an orthogonal solvent for the deposition of P3HT-based HTMs on a perovskite layer, were reported. The percentage in weight of $p$-methoxyphenyl functionalized CNSs with respect to the P3HT is determined by weighting the pellets after the removal of the supernatant, resulting to be 3 and $4 \mathrm{wt} \%$ for the SWCNT- and RGO$\mathrm{PhOMe} / \mathrm{P} 3 \mathrm{HT}$.

The designed HTMs were tested in PSCs, showing an enhancement in photovoltaic performances with respect to PSCs based on simple P3HT. The CNS-P3HT-based HTM increased PSCs stability. In fact, ageing tests, carried out over $3240 \mathrm{~h}$, have shown $\eta$ average of $8.7 \%$ and $4.7 \%$ for SWNTs and RGO-based PSCs.

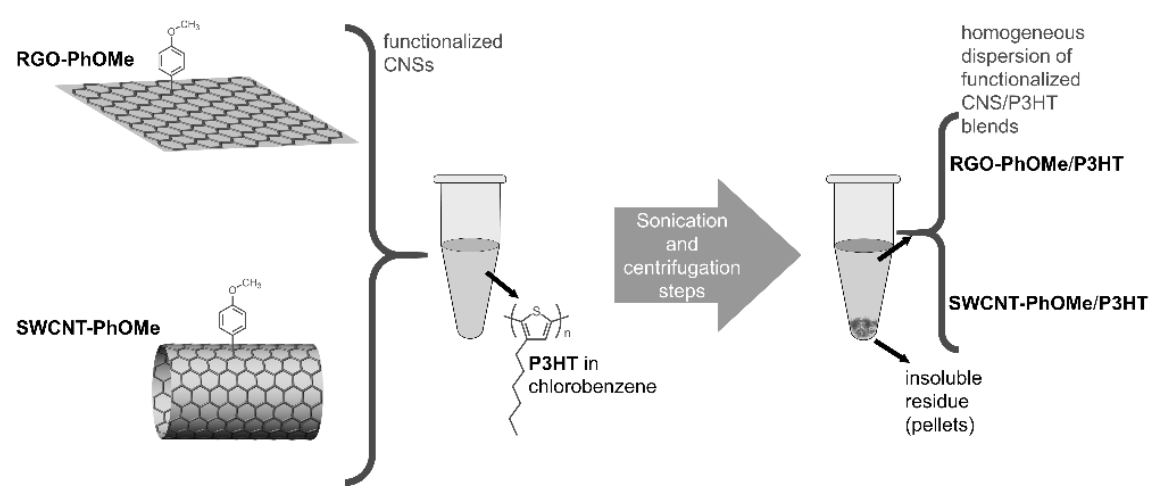

Figure 10. Schematic representation of the sedimentation-based separation process used for the preparation of the $p$-methoxyphenyl functionalized CNS/P3HT blends. Reproduced from Ref. [81] with the permission of Wiley.

Five types of organic moieties reminding the polymeric backbone and alkyl side chains of P3HT have been covalently bound to RGO by Gatti et al. [82] to further improve the effectiveness of the functionalization for RGO@P3HT HTMs in PSCs. The proposed moieties are 4-(thien-2-yl)phenyl (PhTh), 4-(5-methylthien-2-yl)phenyl (PhMeTh), and 4[(2-20-bithiophene)-5-yl]phenyl (PhBiTh) residues, containing thienyl groups recalling the polymer backbone, and the 4-(hexyloxy)phenyl (PhOHex) and 4-[(2-ethyl)hexyloxy]phenyl (PhOEtHex) residues, containing alkyl chains, as in the polymer side-chains (see Figure 11).

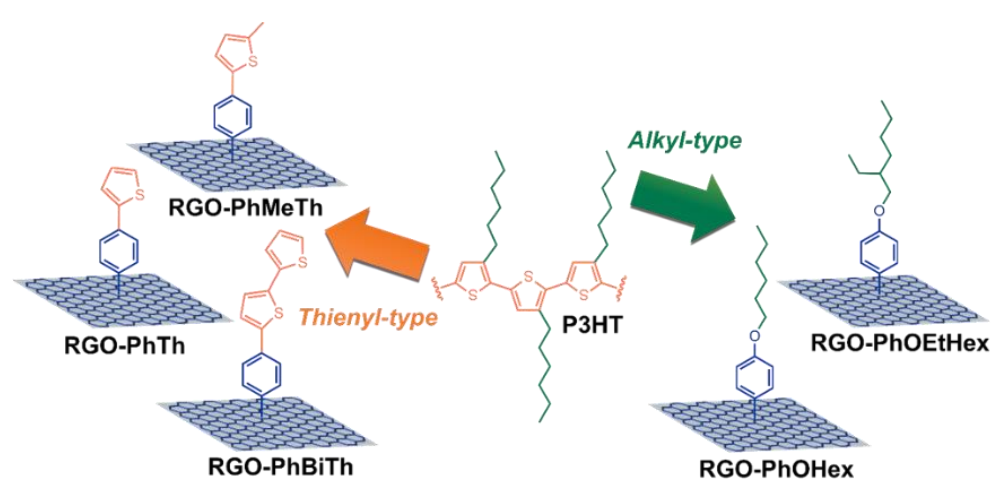

Figure 11. Schematic illustration of the five types of functionalized RGO species reported in this work, highlighting the similarity relationships existing among the organic substituents covalently bound to RGO and the P3HT structure. Reproduced from Ref. [82] with the permission of Wiley.

In situ direct arylation between the corresponding aniline derivative and isoamyl nitrite was used for the synthesis of the organic derivatives. The different reactivity of the aniline precursors led to different FD from 1.2\% in RGO-PhTh to 3.2\% in RGO-PhOHex. The five types of functionalized RGO materials were dispersed in P3HT, starting from a suspension of functionalized RGO/P3HT (1:10 wt/wt; i.e., $10 \mathrm{wt} \%$ ) in chlorobenzene. After removal the insoluble residue, the composite films with the different RGO derivatives 
were casted from final solutions with different wt.\% contents, all exceeding the $4 \mathrm{wt} . \%$ threshold. The chemical nature of the functional groups grafted to RGO has revealed to be crucial in driving PSC efficiency. In fact, the P3HT blend containing functionalizedRGO filler with hexyl chains was found to outperform the PCE and the reproducibility of the other type of composite HTM based on bithienyl decorated RGO and this behaviour was attributed to the different morphology of RGO flakes.

Recently it has been reported that aliphatic polyacrylonitrile-grafted reduced graphene oxide (PRGO) hybrid can function as hole-extraction layer (HEL) in OPV and PSC [87]. The hybrid-structure PRGO was developed by in-situ radiation-induced reduction and graft polymerization with polymerizable styryl-functionalized graphene oxide and acrylonitrile. The synthesis of PRGO was sequentially performed as shown in Figure 12. GO was synthesized from the graphite powder using the well-known modified Hummers method $[88,89]$, and was subsequently functionalized through a carbodiimide-mediated coupling reaction between the $\mathrm{COOH}$ groups of the $\mathrm{GO}$ and the amine of 4-aminostyrene at room temperature to obtain a polymerizable styryl-functionalized GO (FGO) [90]. Finally, a homogenous mixture solution of FGO and acrylonitrile (as a grafting monomer) in dimethylformamide (DMF) was subjected to $\gamma$-irradiation at room temperature to produce highly dispersible PRGO. The active electrons formed from the radiolysis of DMF can deoxygenate FGO and simultaneously initiate the graft polymerization of acrylonitrile at the introduced styryl groups [91-93].
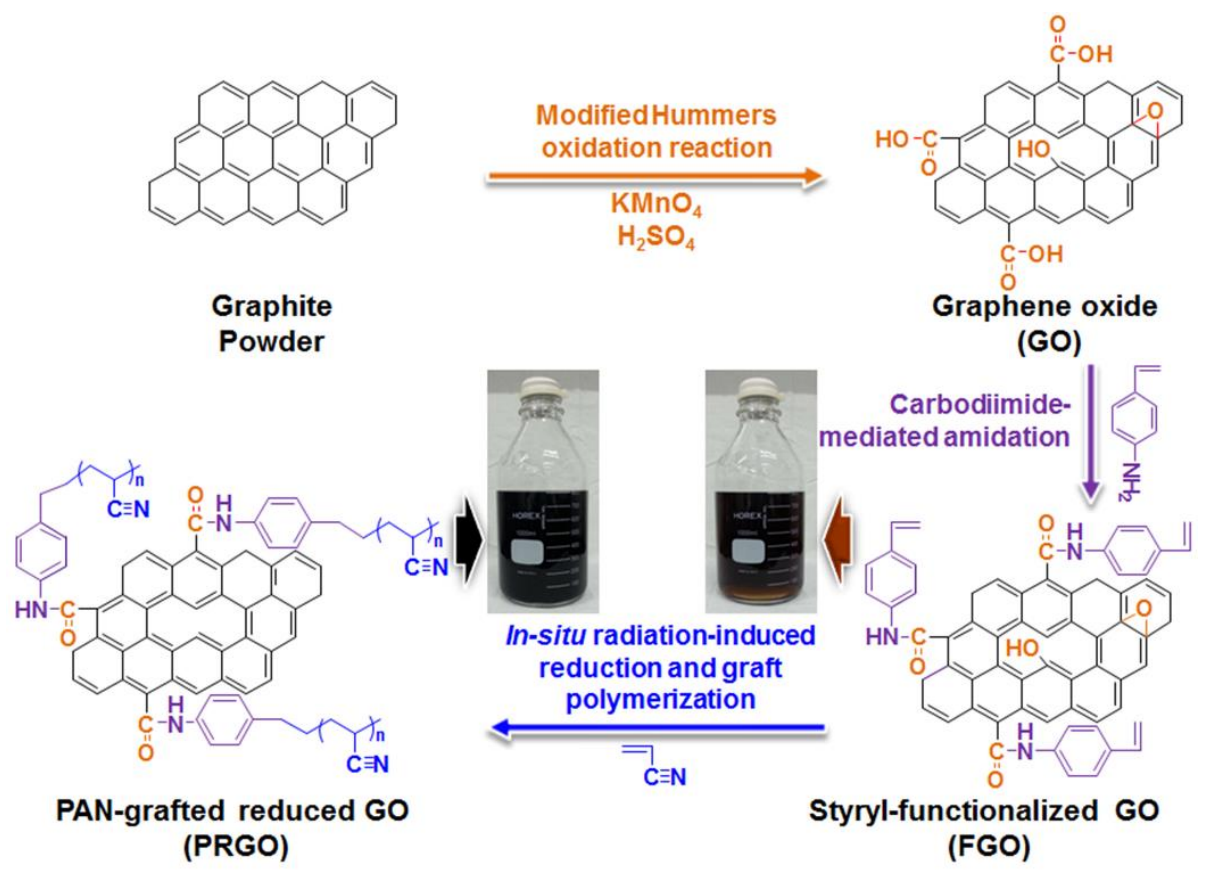

Figure 12. Schematic illustration for the synthesis of PRGO (Insets represent the photograph of the respective FGO and PRGO solutions in $800 \mathrm{ml}$ DMF). Reproduced from Ref. [87] with the permission of Elsevier.

The final PRGO solution had a typical black colour and a grafting degree ranging from 22 to $42 \mathrm{wt} \%$, was obtained by measuring the weight of PRGOs before and after the cleavage reaction of polyacrylonitrile chains from the PRGOs indicating that the grafting degree of PAN can be controlled by the grafting conditions of the monomer concentration and absorbed dose. The formation of the covalently hybrid-structured PRGO was confirmed by Fourier transform infrared spectroscopy, (FT-IR), X-ray photoelectron spectroscopy (XPS), X-ray diffraction spectroscopy (XRD), transmission electron microscopy (TEM), dynamic light scattering (DLS), Raman, ultraviolet-visible spectroscopy (UV-vis), and thermogravimetric analysis (TGA). The comparative analysis confirmed that the polymerizable styryl group was bound to the $\mathrm{COOH}$ of GO, and that PRGO was successfully synthesized via $\gamma$-ray irradiation-induced reduction of FGO and simultaneous graft 
polymerization of acrylonitrile at the styryl groups. The PRGO hybrid material displayed good dispersion stability of six months, even at high concentration of $10 \mathrm{mg} / \mathrm{ml}$ with good film morphology, an electrical conductivity of $0.87 \mathrm{~S} / \mathrm{cm}$, a work function of $4.87 \mathrm{eV}$, and weather stability. A PCE of 7.24\% for PTB7-th based OPV and a PCE of $9.70 \%$ for MAPbI3 based PSC was measured (see Figure 13) with the incorporation of PRGO as HEL these values were comparable to those from the PEDOT:PSS-based PVs but with increased device stability.

(a)

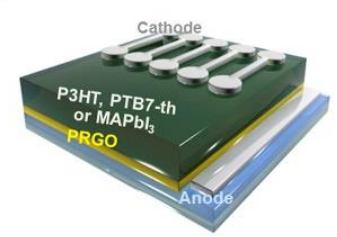

(c)

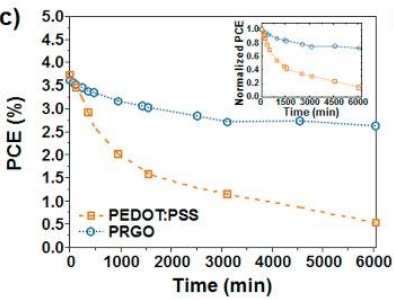

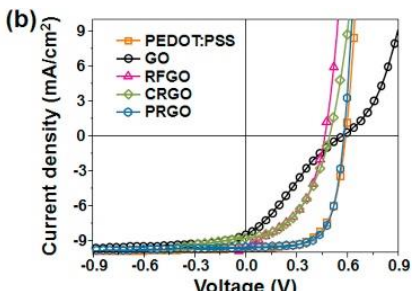

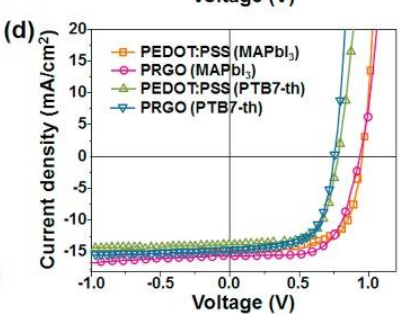

Figure 13. (a) Schematic configuration of P3HT-, PTB7-th- and MAPbI3 perovskite-based PVs with PRGO as a HEL; (b) Representative J-V characteristics of P3HT-based devices with different HELs of PEDOT:PSS, GO, RFGO, and PRGO; (c) PCE decay of P3HT-based PVs with different HELs of PEDOT:PSS and PRGO as a function of exposure time to the ambient atmosphere (The inset shows the normalized PCEs.); (d) Representative J-V characteristics of PTB7-th- and CH3NH3PbI3 perovskite-based PVs with different HELs of PEDOT:PSS and PRGO Reproduced from Ref. [87] with the permission of Elsevier.

Parallel to the covalent functionalization approach, they have been developed new hybrid materials exploiting the non-covalent functionalization strategy.

For this reason, the development of suitable organic molecules able to improve the interaction with organic semiconductors represents a very important point. In 2017 Sartorio and co-workers [94] proposed a series of pyrenyl derivatives as suitable materials to tailor the interaction between SWCNTs and P3HT to be used for electron transfer in thin film heterojunction with P3HT as donor system.

They developed four bifunctional organic derivatives (PyrTh1-4) composed by a pyrene moiety able to interact with CNTs carbon shell and a thiophene unit to improve the affinity with P3HT. The 3-thiopheneethanol and 3-bithiopheneethanol and commercially available pyrene derivatives were selected to obtain the ester derivatives by Steglich esterification with 1-ethyl-3-(3-dimethylaminopropyl)carbodiimide and 4-dimethylaminopyridine (reported in Figure 14). 
(a)

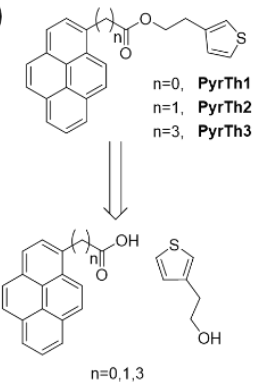

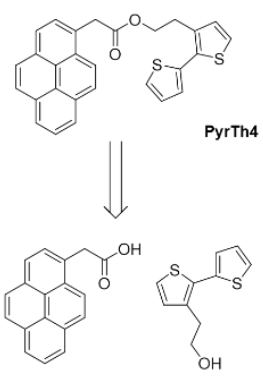

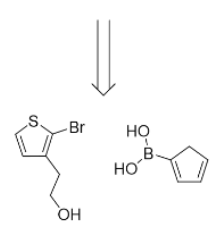

(b)

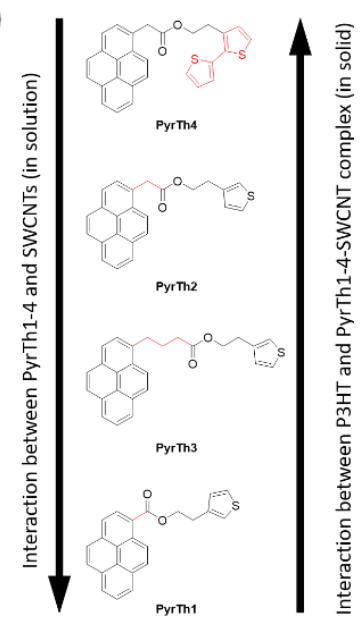

Figure 14. (a) Retrosynthetic approach to the preparation of thiophene derivatives with pyrene pendants: esterification of 3-thiopheneethanol (for derivatives PyrTh1-3) and 3-bitiopheneethanol (for derivative PyrTh4 with carboxylic derivatives of pyrene. Reproduced from Ref. [94] with the permission of Elsevier. (b) Qualitative comparison of the pyrenyl derivatives interaction with SWCNTs as observed by fluorescence quenching of pyrenyl derivatives in SWCNT solution and $\mathrm{P} 3 \mathrm{HT} /$ pyrenyl-derivatives/SWCNTs thin solid films.

The supramolecular interaction in solution was verified via solution fluorescence measurements able to provide a mean to assess the nature (static or dynamic) and the strength of the interaction between CNTs and the bifunctional pyrene-thiophene derivatives in solution.

The analysis of the quenching constants suggested that the interaction with SWCNTs was mainly due to the $\pi-\pi$ interactions of pyrene units with the nanotube surface. The length of the alkyl chains was not relevant while the ester moiety provided a repulsive contribution. The effectiveness of the supramolecular approach was confirmed in solid state by XPS and AFM. The first was used to analyse the chemical composition confirming a good amount of pyrene derivatives per carbon nanostructure while the AFM confirmed the presence of isolated nanotubes.

The weakest interaction with the SWCNTs was obtained for the compound PyrTh1 where ester and pyrene were coplanar while the stronger interaction was obtained for PyrTh4 and PyrTh2 where the $\pi-\pi$ interactions between pyrene and carbon nanostructures were not affected by the presence of the ester group (Figure 14 and Figure 15). As a result, good processability and efficient electron transfer were obtained in thin film heterojunctions system where the alkyl chain was coplanar with the pyrene moiety.

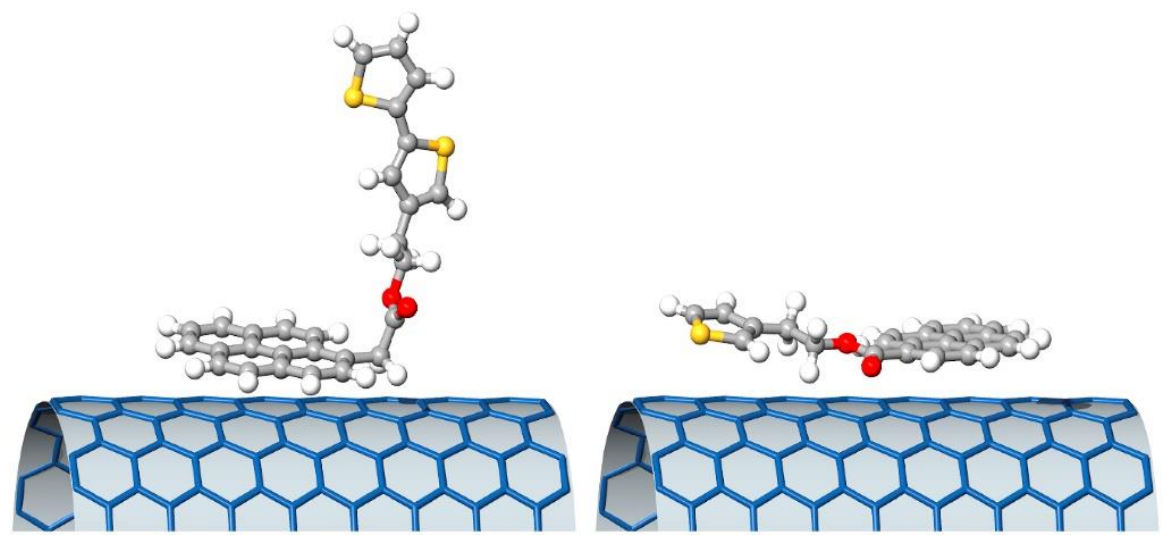

Figure 15. Schematic drawing of the ground state minimum of PyrTh4 (left) and PyrTh1 (right) and of their possible different approaches to the surface of a carbon nanotube. Reproduced from Ref. [94] with the permission of Elsevier. 
A supramolecular green approach was proposed by Hashima et al [95] for the preparation of graphene $\mathrm{TiO}_{2}$ nanohybrid. They proposed an artificially bifunctionalized protein to increase the dispersibility of graphene in water. A variant protein (carbonaceous material binding peptide-Dps-titanium binding peptide (CDT1) $[96,97]$ derived from a Listeria innocua Dps protein synthesized from encoded Escherichia coli was employed [88,98-101]. Dps (DNA-binding protein from starved cells) [102,103] is a cage-shaped protein able to generate inorganic oxides in the inner and outer cavity by biomineralization. The introduction of peptides on the outer surface increased the interaction with graphene and aromatic amino acid parts can bind graphene through $\pi-\pi$ interactions, while carboxylates can coordinate with Ti derivatives on CDT1 promoting the generation of the graphene/ $/ \mathrm{TiO}_{2}$ hybrid. The graphene/CDT1 complex was prepared by simple mixing graphene and CDT1 in a buffer solution via sonication with subsequent washing and centrifugation of the precipitate. The FE-SEM image of the precipitate using a CDT1 with an iron oxide showed the nanosheet structure and $4 \mathrm{~nm}$-size dots on the surface of graphene attributed to CDT1 with Iron oxide adsorbed on graphene surface. (Figure 16) The amount of adsorbed CDT1 on graphene was quantified by the Klotz plots together with the dissociation constants [104] and the adsorption phenomena were attributed to the electrical surface conditions of CDT1 at an optimal $\mathrm{pH}$ around 6.0. The nanohybrid of graphene/CDT1 and $\mathrm{TiO}_{2}$ was prepared by depositing the $\mathrm{TiO}_{2}$ layer on the surface of the graphene/CDT1 complex using as $\mathrm{TiO}_{2}$ precursor (titanium(IV)bis(ammonium lactato)dihydroxide) Ti[BALDH] that was biomineralized by the protein.

(a)

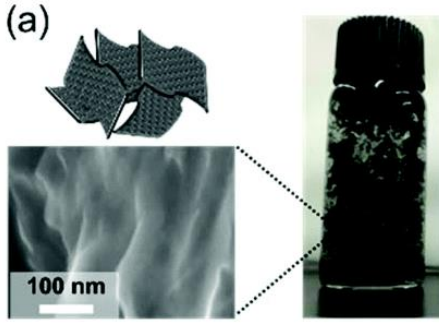

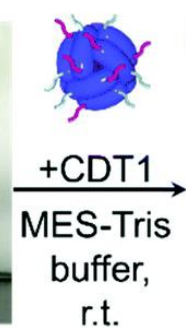

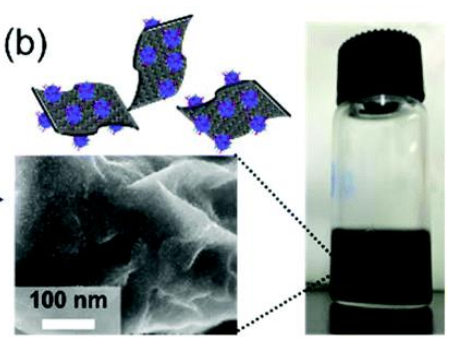

Figure 16. FE-SEM images and photographs of (a) graphene and (b) CDT1 with the iron oxide core adsorbed on graphene. These materials were dispersed in water. Reproduced from Ref. [95] with the permission of the Royal Society of Chemistry.

Transmission Electron microscopy (TEM) and elemental mapping via electron energy-loss spectroscopy confirmed the nano-hybrid formation. PSCs were fabricated using the composite at the interface between FTO electrode and perovskite. The nanohybrid $(0.5$ $\mathrm{wt} \%$ ) was mixed with a meso- $\mathrm{TiO}_{2}$ paste by a sintering process at $450{ }^{\circ} \mathrm{C}$ were $\mathrm{CDT} 1$ was completely burned and the final performance of the device was higher than that of the PSC without the nanohybrid, most probably due to the prevention of electron-hole recombination (see Figure 17).

(a)

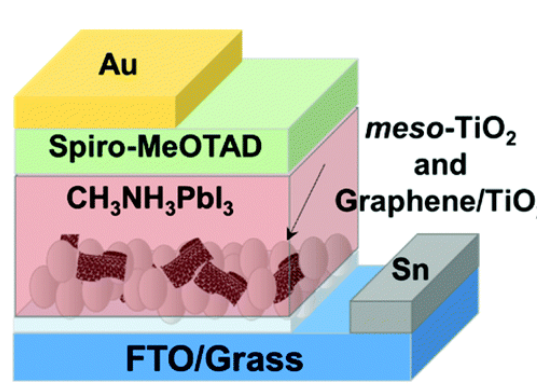

(b)

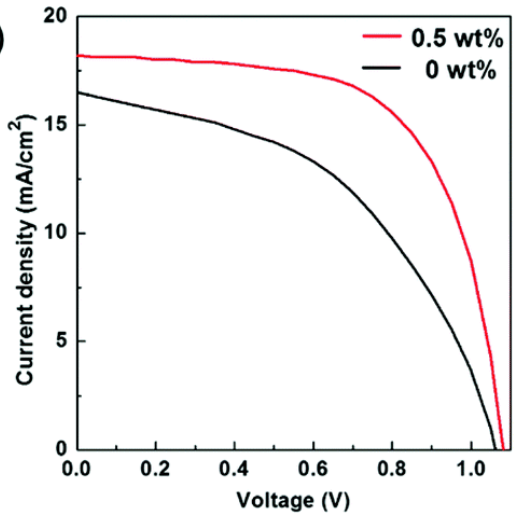


Figure 17. (a) An illustrated structure of the fabricated PSC. (b) I-V characteristics of PSCs with (red line) or without (black line) the graphene/TiO2 nanohybrid in the meso-TiO2 layer. Reproduced from Ref. [95] with the permission of the Royal Society of Chemistry.

The continuous development of organic electronics and the need to replace metals, non-renewable raw materials, with more abundant and renewable materials has led to the demand for alternative transparent electrodes (TCEs) alternatives to Indium-Tin oxide (ITO) which is composed of non-renewable raw materials [105]. Graphene is a very promising alternative material for TCEs thanks to its excellent electrical and optical properties, moreover as carbon-based materials it is renewable and potentially low cost.

The major drawback related to its development is due to the inert nature of graphene responsible for the poor wetting of charge-transporting materials. Jung S. et al. [106] proposed to use the norepinephrine [107] a derivative of catecholamine composed of a hydrophobic benzene ring and hydrophilic functional groups as coating for graphene electrode to increase the wettability.

The graphene film surface was modified via a catechol oxidative polymerization $[108,109]$ by film immersion in a $\mathrm{pH} 8.5$ buffer solution containing norepinephrine(NE) and 2-(2-aminoethoxy)ethanol, which is a hydrophilic primary amine. The intermolecular cross-linking of catechol derivatives was suppressed thanks to the use of a primary amine reacting with oxidized catechol forming catecholamine adducts via Schiff base formation or Michael addition reaction, resulting in the formation of a smooth thin film of polyNE. Moreover the hydroxyl group in the 2-(2-aminoethoxy)ethanol molecule add an extra hydroxyl group to the polyNE coating layer increasing the hydrophilicity of the surface as confirmed by water contact angle (Figure 18).

a

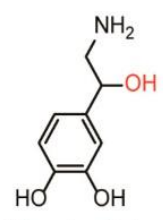

Norepinephrine

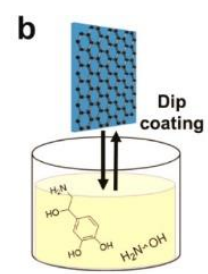

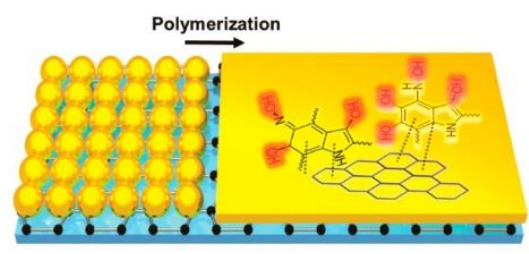

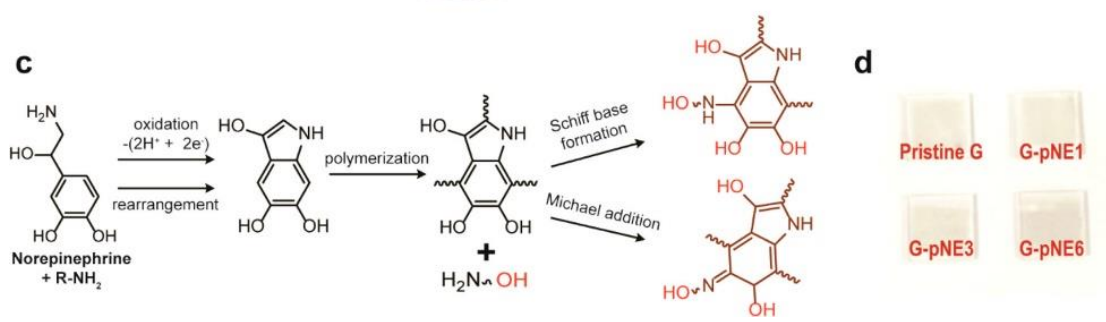

C

Figure 18. Formation of the polyNE film on graphene. (a) Molecular structure of norepinephrine. (b) Schematic of the process of coating and polymerization of norepinephrine on graphene. (c) Scheme for the polymerization pathway of norepinephrine. (d) Digital image of pristine and pNEcoated graphene on glass substrates. Reproduced from Ref. [106] with the permission of the American Chemical Society.

For devices applications a film thickness of less than $10 \mathrm{~nm}$ was used to minimize the insulating effect of the polyNE and an annealing treatment to improve the film quality was performed. The thermal treatment did not cause a significant change in chemical composition while improved the overall conductivity of the film by reducing the vacant spaces and improving the contact between the graphene and polyNE. The modified hydrophilic graphene surface allowed good coverage of a conventional HTM as PEDOT:PSS and as a result efficient graphene-based OSCs were prepared with performance comparable to that of the ITO reference device as reported in Figure 19. 
a
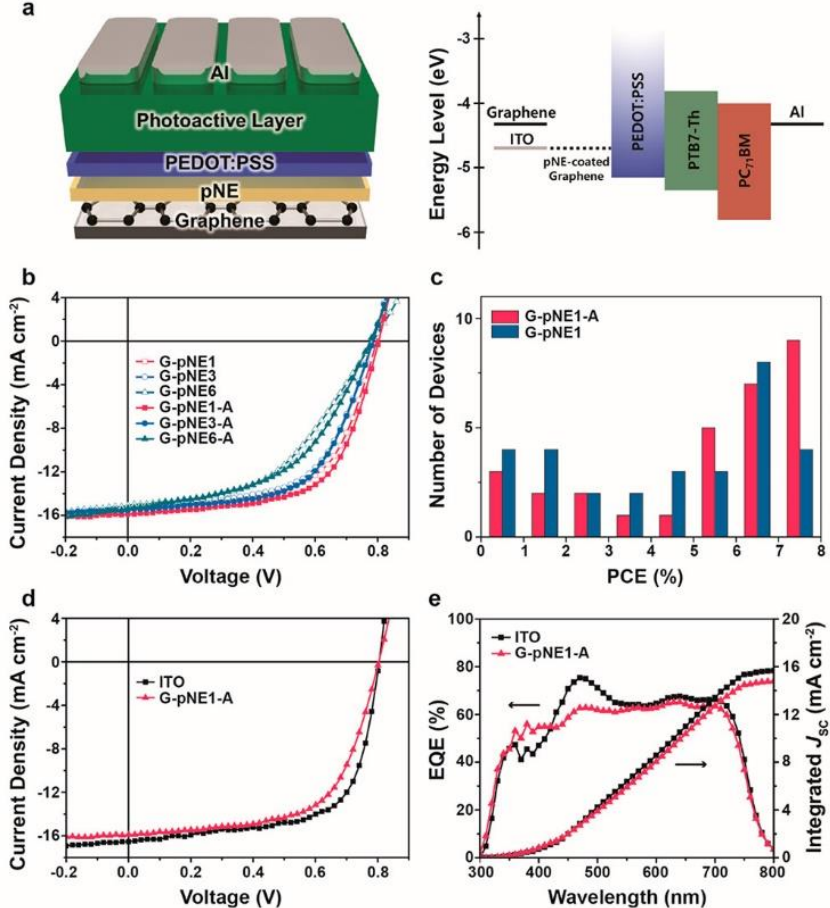

Figure 19. Device performance of the pNE-coated graphene-based OSCs. (a) Schematic of the conventional device and the corresponding flat-band energy-level diagram. (b) J-V characteristics of the pNE-coated graphene-based OSCs with and without the annealing treatment. (c) Performance statistics for the OSCs with and without annealing. (d) J-V characteristics and (e) EQE measurements with corresponding integrated Jsc of the device with the best performance (G-pNE1-A) compared with those of the ITO reference. Reproduced from Ref. [106] with the permission of the American Chemical Society.

\section{Photocatalytic fuel production}

Using solar energy to produce fuels (typically hydrogen) can be a convenient route to reduce pollution and carbon footprint, bringing the advantage of storing energy in a stable way until it will be consumed, for example in electric vehicles equipped with fuel cells [110]. CNSs have been proposed for years as components of photocatalytic systems for the production of $\mathrm{H}_{2}$, based on both inorganic semiconductors and organic dyes $[8,111]$.

Most recent investigations in the field are focused on hybrid photocatalysts based on graphene-based materials. Porphyrins and phthalocyanines, due to their intense absorption in the visible-light region and efficient photoinduced electron donation ability, are very promising organic photoactive moieties for hydrogen evolution. Moreover, their structure offers the possibility to form stable bonds with CNSs, either covalent or noncovalent.

Among graphene-based materials, GO offers a plethora of oxygen-based functional groups for the grafting of molecules. Oxygen itself can coordinate the metal of a porphyrin complex, like in the example reported by Ping and coworkers [112]. The authors synthesized a hybrid material with a manganese tetraphenylporphyrin (MnTPP) covalently linked to GO by simply reacting $\mathrm{MnTPPCl}$ and $\mathrm{GO}$ at $85^{\circ} \mathrm{C}$ for 5 days in pyridine. The covalent bond has been confirmed by XPS, FTIR (showing a peak for Mn-O vibration) and Raman (with a red-shift of $\mathrm{D}$ and $\mathrm{G}$ bands due to the attached electron donor porphyrin). Under UV-vis irradiation in water, the system exhibited significant $\mathrm{H}_{2}$ evolution $(3.8 \mu \mathrm{mol}$ $\mathrm{mg}^{-1}$ after 6 hours of UV-vis irradiation). The system was then modified by depositing $\mathrm{Pt}$ nanoparticles on $\mathrm{GO}$, though in situ photoreduction of a $\mathrm{H}_{2} \mathrm{PtCl}_{6}$ solution, leading to an enhancement of photocatalytic activity $\left(4.6 \mu \mathrm{mol} \mathrm{mg}^{-1}\right)$, thanks to a lowering of the electrochemical overpotential. A further enhancement of hydrogen evolution $\left(5.2 \mu \mathrm{mol} \mathrm{mg}^{-1}\right)$ was achieved after addition of polyvinyl pyrrolidone (PVP) as surfactant, leading to a more homogeneous dispersion and to a larger available active surface. 
Time resolved optical spectroscopy suggests a rapid photoinduced electron transfer from the sensitizer molecule MnTPP to GO, allowed by the direct linkage (see Figure 20). The proposed mechanism involves a subsequent electron transfer to Pt nanoparticles, where $\mathrm{H}+$ is reduced to $\mathrm{H}_{2}$. The oxidized porphyrin moiety is then regenerated by a sacrificial donor $(\mathrm{TEA}=$ triethylamine $)$.

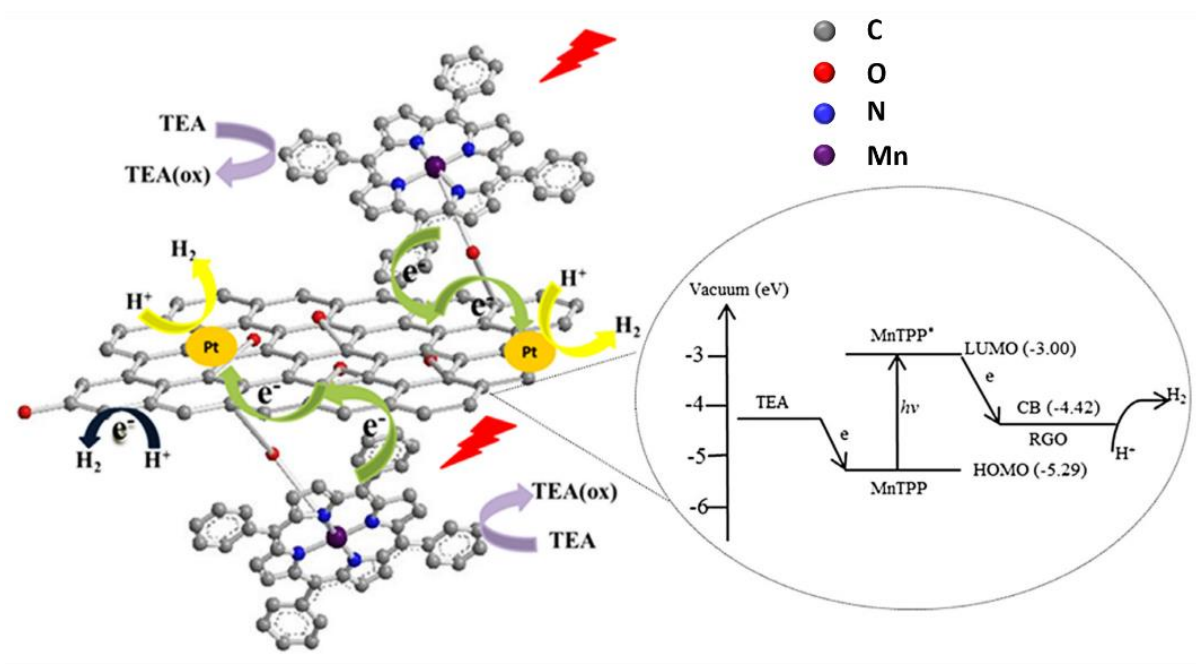

Figure 20. Diagram of the proposed photocatalytic mechanism for GO-MnTPP/Pt. Reproduced from Ref. [112] with the permission of World Scientific.

Using GO as supporting matrix, given its excellent properties as electron mediator, enhances electron transfer processes and prevents charge recombination.

Carboxylic groups, ubiquitous in GO structure, can be used to graft amine-functionalized porphyrins through amide bond formation [113]. Following this approach Yan and coworkers functionalized GO with an aminated tetraphenylporphyrin (TPP-NH 2$)$ photosensitizer [114]. To activate GO, it was refluxed in $\mathrm{SOCl}_{2}$ in the presence of DMF for $24 \mathrm{~h}$ under argon. After purification, the product was reacted with TPP-NH 2 in DMF at $130{ }^{\circ} \mathrm{C}$ for $72 \mathrm{~h}$ under argon. In addition, [FeFe]-hydrogenase model (IHM) complexes (as proton reduction catalysts) where linked to the basal plane of GO through non-covalent $\pi-\pi$ interactions with the aromatic ring of the complex, inspired by a previous work on biomolecular photocatalysts [115]. 


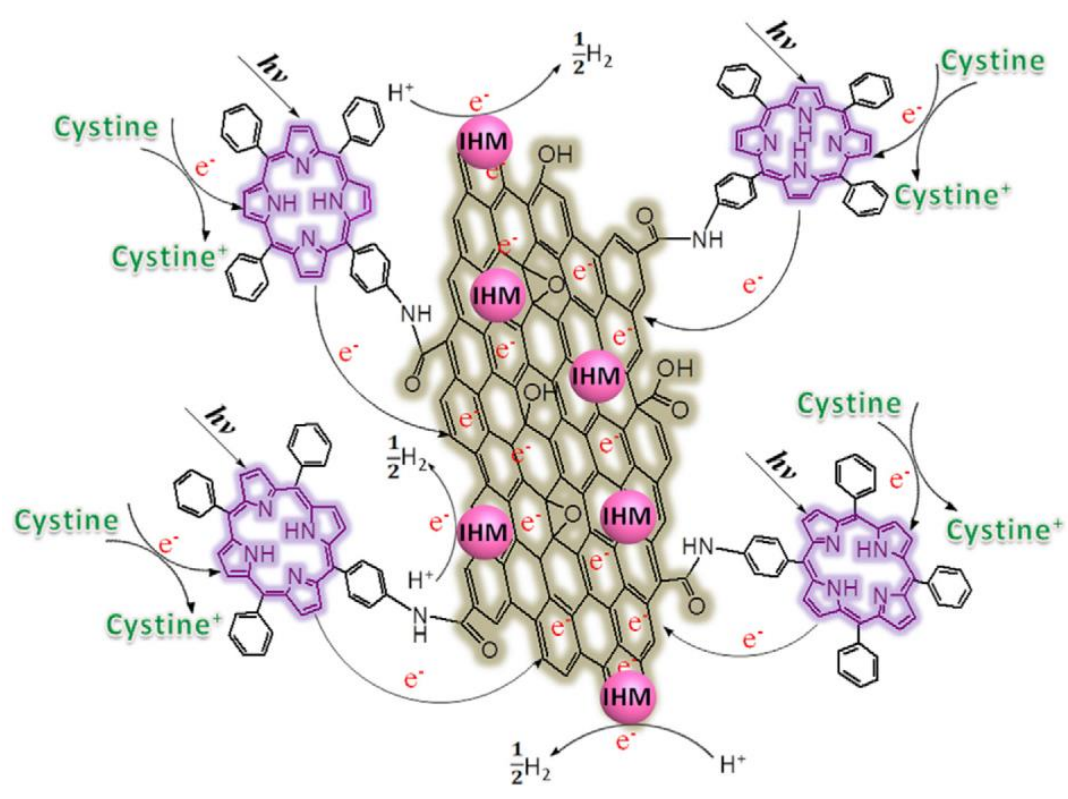

IHM $=[$ FeFe]-hydrogenases model

Figure 21. The proposed mechanism of photocatalytic $\mathrm{H}_{2}$ production for a catalytic system based on GO, a porphyrin sensitizer and a biomimetic catalyst. Reproduced from Ref. [114] with the permission of Elsevier.

The biomimetic photocatalytic system resulting from the double decoration benefits from the electron mediation operated by GO between the photosensitizer and the catalytic unit, thus showing enhanced hydrogen evolution. Moreover, GO hydrophilicity improves dispersion of TPP and of the catalytic complex in water/ethanol. A schematic representation of the proposed photocatalytic $\mathrm{H}_{2}$ production mechanism is reported in Figure 21. Cystine was chosen as a sacrificial donor to simulate a biological protein environment. The proposed working principle is supported also by emission spectroscopy, showing fluorescence quenching by $80.6 \%$ when TPP is bound to GO, probably due to electron transfer from the dye to the nanostructure. The pivotal role of covalent functionalization with the organic sensitizer was highlighted by control experiments where the porphyrin was just adsorbed on GO, affording less efficient hydrogen production.

The use of amide bonds is also reported by Wang and coworkers, in a study focused on materials with non-linear optical properties that could be promising candidates also for photocatalytic hydrogen generation, although this was not proved [116]. The authors grafted a porphyrin-based polymer (ZnTNP-PAES) to the carboxylic groups on GO to obtain a photoactive hybrid (PF-GO, see Figure 22). They also used a similar strategy, but based on ester bonds, to functionalize GO with 5-(4-hydroxyphenyl)-10,15,20-trinaphthylporphyrin zinc (ZnTNP-OH) to obtain ZnP-GO (see Figure $22 \mathrm{~b}$ ).

ZnTNP-PAES is a copolymer of phenyl sulfone, (p-amino)-phenylhydroquinone, and a symmetrical zinc dinaphthylporphyrin. Aminated moieties on the copolymer are reacted with $\mathrm{COOH}$ groups on $\mathrm{GO}$ to form amide bonds, while the abundant aromatic rings in the backbone can establish strong $\pi-\pi$ interactions with GO basal plane, thus stabilizing the hybrid, preventing aggregation of the nanosheets and improving their dispersion. To obtain the hybrids, the authors first activated GO through reaction with $\mathrm{SOCl}_{2}$. The obtained acyl chloride derivative GO-COCl was then reacted, in anhydrous DMF and trimethylamine at $80^{\circ} \mathrm{C}$ for $72 \mathrm{~h}$ under argon, with ZnTNP-PAES or with ZnTNP-OH to obtain PF-GO or ZnP-GO respectively. Chemical stability of porphyrins and related structures allowed a further chemical transformation of the hybrid. Indeed, PF-GO was reduced with hydrazine to obtain the corresponding RGO/polymer hybrid PF-RGO. 


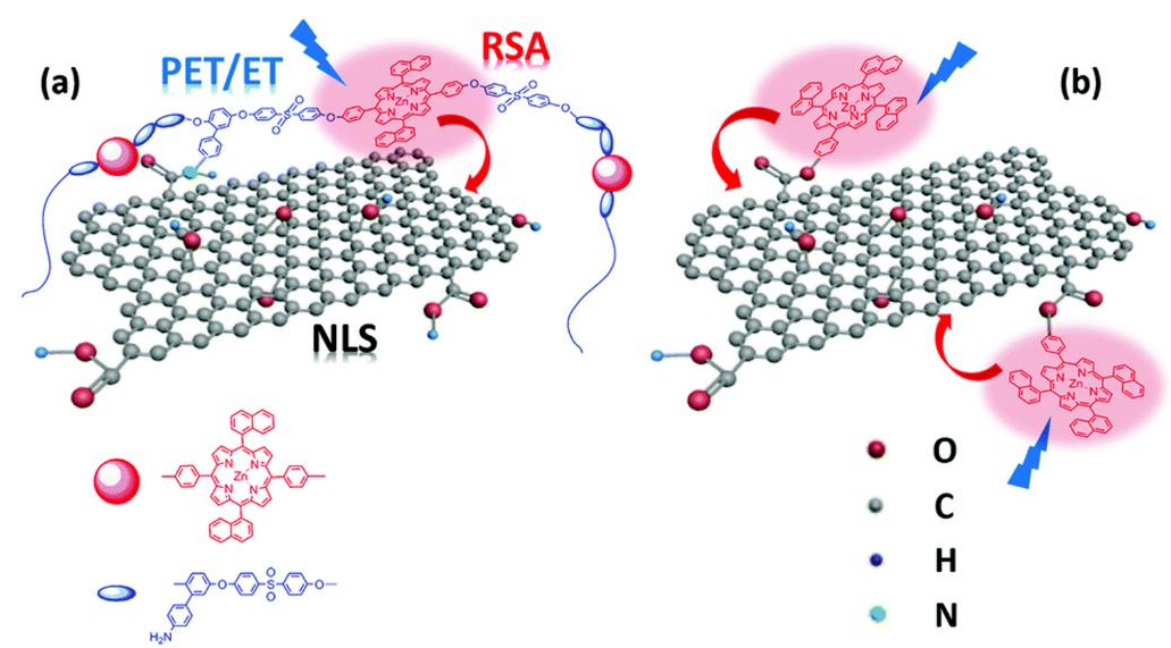

Figure 22. Schematic representation of structures and photoactivity for PF-GO (a) and ZnP-GO (b) Reproduced from Ref. [116] with the permission of the Royal Society of Chemistry.

Photophysical investigations on porphyrin hybrids, compared to starting polymer and porphyrin, revealed features such as relevant fluorescence quenching (65\% and $57 \%$ for PF-GO and ZnP-GO respectively, and even more for RGO hybrids) and decreased lifetimes of excited states that are indicative of energy or electron transfer processes, thus opening the possibility to consider them for solar energy conversion and in particular for photocatalytic applications in analogy with other porphyrin-CNS derivatives [117].

Another covalent approach, based on Prato reaction, was used by Lu and coworkers to prepare a hybrid material with a manganese phthalocyanine grafted to graphene, which in turn was obtained through mechanical exfoliation of graphite [118]. In details, the 1,3 dipolar cycloaddition reaction with $N$-methyl-glycine and 4-hydroxybenzaldehyde afforded a graphene-pyrrolidine derivative with a phenol group that, after $\mathrm{OH}$ deprotonation with $\mathrm{K}_{2} \mathrm{CO}_{3}$, was reacted with the manganese phthalocyanine chloride to form the hybrid complex MnPcG (represented in Figure 23) through formation of a Mn-O bond.

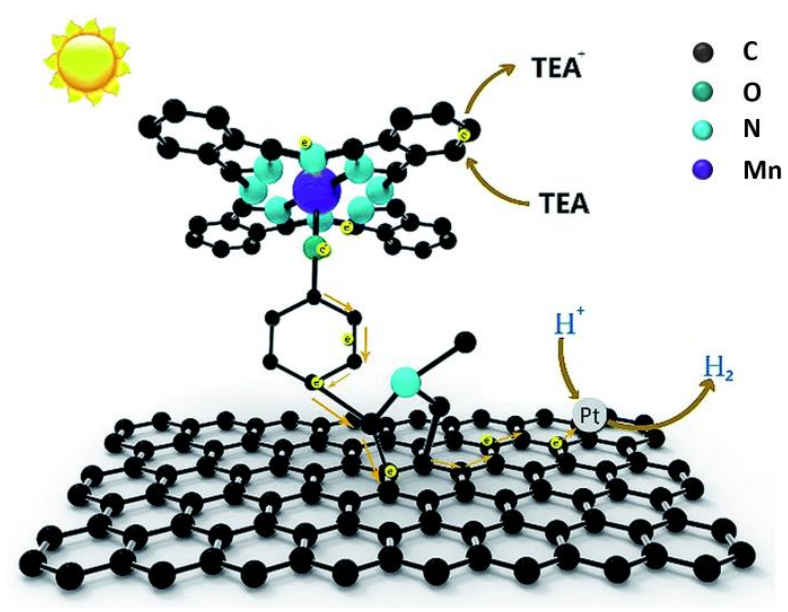

Figure 23. Schematic representation of MnPcG complex and of its photocatalytic activity in the presence of Pt nanoparticles and triethylamine (TEA) as sacrificial reducing agent. Reproduced from Ref. [118] with the permission of the Royal Society of Chemistry.

An efficient photocatalytic hydrogen production from water was observed (7.52 $\mu \mathrm{mol} \mathrm{mg}{ }^{-1}$ after 10 hours of UV irradiation), and the importance of covalent functionalization was highlighted by comparison with a simple mixture of graphene and manganese phthalocyanine chloride, which afforded $7.52 \mu \mathrm{mol} \mathrm{mg}{ }^{-1}$. Like in the case of GO-MnTPP, hydrogen evolution further increased after decoration of graphene sheets of the complex with $\mathrm{Pt}$ nanoparticles, through in situ photoreduction of $\mathrm{H}_{2} \mathrm{PtCl}_{6}$. A similar photocatalytic 
mechanism as for GO-MnTPP/Pt was proposed, as depicted in Figure 23, and also in this case the CNS plays the role of a substrate supporting the organic sensitizer and enhancing electron transfer to the catalytic site thanks to superior electronic properties offered by the $\mathrm{sp}^{2}$ carbon lattice. Moreover, the overall structure of the covalent hybrid seems to contrast recombination, thus extending the lifetime of photogenerated separated charges and eventually improving hydrogen reduction efficiency.

Notwithstanding the relevance of covalent linkages between sensitizer and CNS, large aromatic systems like porphyrins also offer the possibility of relatively strong noncovalent interactions with the basal plane of grafene-based materials. This is the case of the hybrids obtained by Lewandowska et al. by mixing a GO solution in water and a porphyrin solution in THF [119]. Resulting $\pi-\pi$ stacking interactions were accounted for the observed quenching of fluorescence, but they leaved other properties of the porphyrin unaffected. Overall spectroscopic evidences, including EPR measurements, and density functional theory (DFT) calculations suggest that the porphyrin-GO complex can be used as an active material for applications based on photoinduced electron transfer processes.

A similar non-covalent interaction, involving RGO and an heme moiety, is supposed to be at the basis of a bio-hybrid system, obtained by Yong and coworkers, showing photocatalytic $\mathrm{H}_{2}$ production [120]. In this case, the organic molecular component is replaced by whole bacterial cells (Shewanella oneidensis) deposited on RGO sheets previously decorated with $\mathrm{Cu}_{2} \mathrm{O}$ clusters (Figure 24). Supported by time resolved photoluminescence investigations and DFT calculations, the authors detected electron transfer processes, enabling photocatalytic hydrogen evolution, enabled by hydrophobic interactions between RGO and membrane-bound redox proteins (MtrC/OmcA) and in particular their heme moiety.

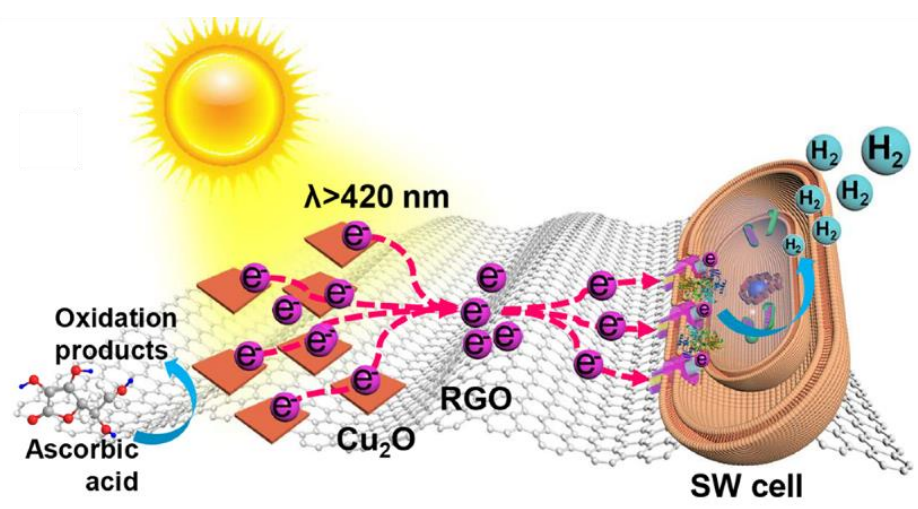

Figure 24. Schematic illustration of charge separation and transfer giving rise to hydrogen evolution under visible light irradiation in a RGO based bio-hybrid including Shewanella oneidensis (SW) bacteria. Reproduced from Ref. [120] with the permission of the American Chemical Society.

The proposed mechanism involves a photoinduced charge separation at $\mathrm{Cu}_{2} \mathrm{O}$ and a subsequent electron flow, mediated and enhanced by RGO, to the redox proteins embedded in cell membranes, where hydrogen reduction takes place. Indeed, photocatalytic $\mathrm{H}_{2}$ production efficiency of the bio-hybrid $\left(322.0 \mu \mathrm{mol} / \mathrm{g}_{\mathrm{Cu}_{2} \mathrm{O}}\right.$ after $4 \mathrm{~h}$ of visible-light irradiation) was at least 11 times higher than model $\mathrm{Cu}_{2} \mathrm{O} /$ bacteria hybrids without $\mathrm{RGO}$. Moreover, control experiments with deletion of the MtrC/OmcA proteins in the cells afforded no $\mathrm{H}_{2}$ evolution, thus confirming the proposed photocatalytic mechanism.

Even inside the cavity of a SWCNT, a photoactive molecule like a ferrocenyl dye can absorb light and give rise to photoinduced electron transfer to a fullerene derivative (a water-soluble fullerodendrimer [121]) adsorbed on the outer side of the wall, as reported by Takaguchi and coworkers [122]. Encapsulation was achieved by refluxing SWCNTs and the ferrocenyl derivative in 1,2-dimethoxyethane for $3 \mathrm{~h}$, followed by filtration and careful washing of the product to remove any molecule sticking to the outer wall of the tubes. Non-covalent adhesion of the fullerene derivative was then achieved by sonicating 
a dispersion of the endohedral SWCNT derivative in a water solution of the fullerodendron for $4 \mathrm{~h}$ at room temperature. The obtained hybrid acts as a photosensitizer in the presence of methyl viologen (MV) cations, 1-benzyl-1,4-dihydronicotinamide (BNAH), and Pt nanoparticles. Upon photoexcitation, the encapsulated dye donates one electron to the fullerene, while the hole left over on the dye is transferred to the SWCNT. Mediated by the couple $\mathrm{MV}^{2+} / \mathrm{MV}^{+}$, the electron is then transferred to the Pt nanoparticle where it reduces $\mathrm{H}^{+}$to $\mathrm{H}_{2}$. On the other side, $\mathrm{BNAH}$ acts as a sacrificial reducing agent and donates one electron to the SWCNT to regenerate the photocatalytic system. Hydrogen generation in this case is only used as a proof of concept to demonstrate, for the first time, a PET occurring through the wall of a SWCNT. Once again, functionalization plays a relevant role, in a system based on different non-covalent interactions between a SWCNT and two molecules, inside and outside the tube. The same team reported very recently an evolution of this system, where the nanopeapods was rendered dispersible in water through non-covalent exohedral functionalization with solubilizing dendrimers [123].

Over the last years researchers have been increasing their focus on the production of carbon nanomaterials starting from biomass or food waste, as a sustainable approach that lowers carbon footprint and embraces circular economy paradigms. In this frame, it is worth mentioning an unusual example of hybrid photocatalytic system for hydrogen evolution based on porous biomass carbon (PBC) [124]. In the work reported by Chen and coworkers, organic functionalization in a strict sense is not involved, but rather the organic components in the biomass (kemp) are converted into N-doped porous carbon. Natural sea kemp collected in Dalian (China), which nitrogen content was evaluated to be $5.84 \%$ with respect to carbon, was calcinated under a $\mathrm{N}_{2}$ flow at $800^{\circ} \mathrm{C}$ and activated with a $\mathrm{KOH}$ solution, and then neutralized, rinsed and dried. The resulting PCB substrate was first coated with a MoS4- layer and then with $\mathrm{Co}^{2+}$ by means of solution treatments with $\left(\mathrm{NH}_{4}\right)_{2} \mathrm{MoS}_{4}$ and $\mathrm{Co}\left(\mathrm{NO}_{3}\right)_{2} \cdot 6 \mathrm{H}_{2} \mathrm{O}$ salts respectively. The resulting material was then subjected to a hydrothermal treatment that afforded a PBC supported $\mathrm{MoS}_{2}$ catalyst co-doped with $\mathrm{Co}$ and $\mathrm{N}$, the latter migrated from the biomass-derived carbon (see process scheme in Figure 25).

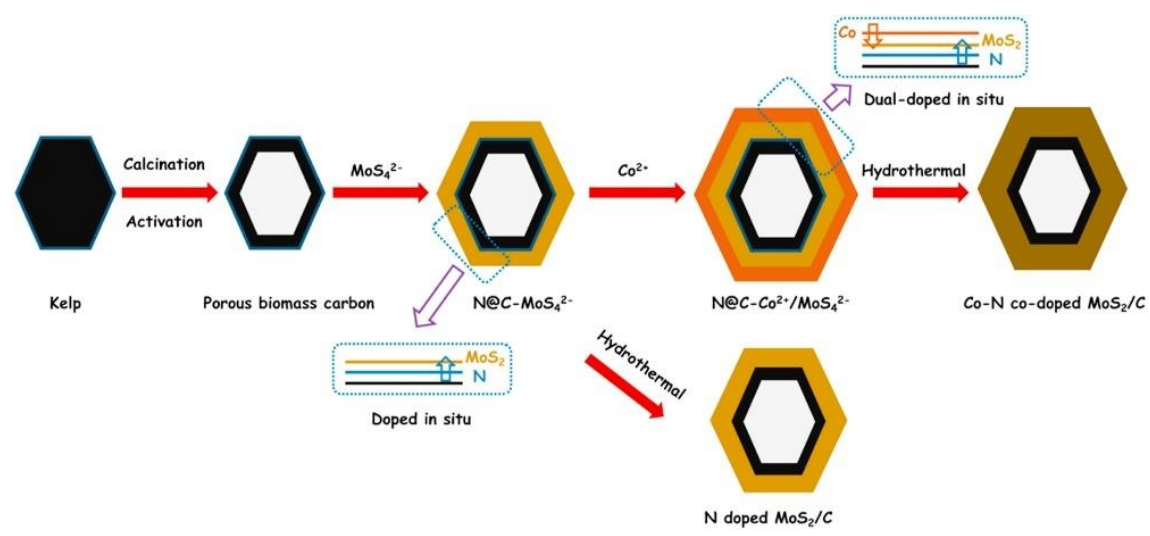

Figure 25. Schematic illustrations of the preparation processes of the $\mathrm{Co} / \mathrm{N}$ dual-doped-MoS2/C heterostructure composite. Reproduced from Ref [124] with the permission of Elsevier.

Peculiarity of this sustainable approach is the conversion of the bio-organic material into a conductive substrate that facilitates electron transfer processes, thus leading to photocatalytic hydrogen evolution, and at the same time enables doping of the inorganic semiconductor, since the biomass is a source of both carbon and nitrogen.

\section{Conclusions and/or perspectives}

In this review we have tried to provide a comprehensive overview on the use of functionalized organic carbon nanostructures for solar energy conversion. Our attention has focused in particular on the most recent contributions given by organic chemistry to the 
development of new hybrid materials that find application in DSSC, OPV and PSC and in photocatalytic fuel production.

The interest in carbon-based nanomaterials has developed thanks to their exceptional electrical/thermal conductivity, high chemical stability and mechanical strength. Furthermore, the possibility of engineering their structures through covalent and non-covalent chemical functionalization, has made it possible to correct some of their drawbacks such as poor solubility, tendency to aggregate and poor quality of the films. The chemical functionalization is also able to modulate their optical and electronic properties by combining them with those of the materials with which they are in contact, and this makes them an even more versatile platform for new functions or components with possible synergistic effects.

The request for new materials able to accompany the green energy transition that are abundant, low cost, with low toxicity, from renewable sources has further increased the interest in CNSs that meet all these requirements. In particular, as highlighted in this review, it is possible to disperse them in water, eliminating the use of toxic solvents while maintaining excellent electrical characteristics. Furthermore, their use generally leads to devices with characteristics that are equivalent if not superior to traditional ones, but in general they improve the stability over time. This feature combined with low cost and good availability is crucial to allow the industrial diffusion of organic and hybrid systems for energy conversion.

So far, the selected literature works clearly demonstrate that the inclusion of an organic molecule, thank to both covalent and non-covalent interaction, into a carbon nanostructure, leads to the formation of a completely new material which can be characterize by better spectroscopic absorbance, improved conductivity and/or enhanced photocurrent density. Besides the numerical data, which unequivocally state the positive effect of the new material, we hope that these examples can be inspiring for further research in the field of photoactive materials from an organic point of view.

Funding: This research was funded by "Centro Studi di Economia e Tecnica dell'Energia Giorgio Levi Cases" (project PRINTERS) and Department of Chemical Sciences (project PDISC\#06BIRD2019-UNIPD) of the University of Padova, and by Regione Lombardia Project "Piattaforma tecnologica per lo sviluppo di sonde innovative in ambito biomedicale" (ID 244356)..

Conflicts of Interest: “The authors declare no conflict of interest."

\author{
Abbreviations and acronyms \\ AFM atomic force microscopy \\ BNAH 1-benzyl-1,4-dihydronicotinamide \\ CDT1 carbonaceous material binding peptide-Dps-titanium binding peptide \\ CHP 1-cyclohexyl-2-pyrrolidone \\ CNS carbon nano-structure \\ CNT carbon nanotube \\ DFT density functional theory \\ DLS dynamic light scattering \\ DMF dimethylformamide \\ Dps DNA-binding protein from starved cells \\ DSSC dye-sensitized solar cell \\ D- $\pi$-A donor- $\pi$-acceptor system \\ EPR electron paramagnetic resonance spectroscopy \\ EQE external quantm efficiency \\ ETM electron transporting Materials
}


ETM electron transporting materials

FD functionalization degree

FGO polymerizable styryl-functionalized GO

f-MWCNTs-PIN carboxylic acid-functionalized multi-walled carbon nanotubes-polyindole

FT-IR Fourier-transform infrared spectroscopy

FTO glass

GBM graphene-based materials

GDQ graphene quantum dot

GO graphene oxide

GQD graphene quantum dots

$\mathrm{H}_{2} \mathrm{SO}_{4}$ sulfuric acid

HEL hole-extraction layer

HiPco High-pressure carbon monoxide

$\mathrm{HNO}_{3}$ nitric acid

HOMO highest occupied molecular orbital

HTM (Hole transporting Materials)

IHM [FeFe]-hydrogenase model complex

ITO indium tin oxide electrode

Jsc short current density

LUMO lowest unoccupied molecular orbital

MnPcG manganese phthalocyanine GO hybrid

MnTPP tetraphenylporphyrin

MOCPc metallo-octacarboxyphthalocyanines

MOF metal organic framework

MPC metallophthalocyanines

MtrC/OmcA membrane-bound redox proteins

MV methyl viologen

MWCNT multi walled carbon nanotube

N719 Di-tetrabutylammonium cis-bis(isothiocyanato)bis(2,2'-bipyridyl-4,4'-dicarboxylato)ruthenium(II)

NE norepinephrine

$\mathrm{NH}_{2}$-TPA-Th-H triphenylamine-thiophene-cyan acrylic acid

NMR nuclear magnetic resonance

OPV organic photovoltaics

P3HT poly-3-hexyl-thiophene

PBC porous biomass carbon

PCE power conversion efficiency

PEDOT:PSS poly(3,4-ethylenedioxythiophene)polystyrene sulfonate

PhBiTh 4-[(2-20-bithiophene)-5-yl]phenyl

PhMeTh 4-(5-methylthien-2-yl)phenyl

PhOEtHex 4-[(2-ethyl)hexyloxy]phenyl 
PhOHex 4-(hexyloxy)phenyl

PhOMe anisole

PhTh 4-(thien-2-yl)phenyl

PIN polyindole

polyNE Poly- norepinephrine

PRGO polyacrylonitrile-grafted reduced graphene oxide

PSC perovskites solar cells

RGO reduced graphene oxide

rGO reduced graphene oxide

SWCNT single walled carbon nanotube

TCE Transparent conducting electrode

TEA triethylamine

TEM transmission electron microscopy

TGA thermo gravimetric analysis

Ti[BALDH] titanium(IV)bis(ammonium lactato)dihydroxide)

$\mathrm{TiO}_{2}$ Titanium dioxide

TPA-Et methyl-2-cyano-3-(4-(diphenylamino)phenyl)acrylate

TPP tetraphenylporphyrin

TPP-NH 2 tetraphenylporphyrin

UV-vis ultraviolet-visible spectroscopy

UV-Vis-NIR ultraviolet-visible-near infra-red

Voc open circuit voltage

XPS X-ray photoelectron spectroscopy

XRD X-ray diffraction spectroscopy

ZnTNP-OH 5-(4-hydroxyphenyl)-10,15,20-trinaphthylporphyrin zinc

ZnTNP-PAES copolymer of phenyl sulfone, (p-amino)-phenylhydroquinone, and zinc dinaphthylporphyrin

\section{References}

1. Ganesamoorthy, R.; Sathiyan, G.; Sakthivel, P. Review: Fullerene based acceptors for efficient bulk heterojunction organic solar cell applications. Sol Energ Mat Sol C 2017, 161, 102-148, doi:10.1016/j.solmat.2016.11.024.

2. Po, R.; Maggini, M.; Camaioni, N. Polymer Solar Cells: Recent Approaches and Achievements. Journal of Physical Chemistry C 2010, 114, 695-706, doi:10.1021/jp9061362.

3. Thompson, B.C.; Frechet, J.M.J. Organic photovoltaics - Polymer-fullerene composite solar cells. Angewandte ChemieInternational Edition 2008, 47, 58-77, doi:10.1002/anie.200702506.

4. Gatti, T.; Menna, E.; Meneghetti, M.; Maggini, M.; Petrozza, A.; Lamberti, F. The Renaissance of fullerenes with perovskite solar cells. Nano Energy 2017, 41, 84-100, doi:10.1016/j.nanoen.2017.09.016.

5. Gatti, T.; Menna, E. Use of Carbon Nanostructures in Hybrid Photovoltaic Devices. In Photoenergy and Thin Film Materials, Yang, X.-Y., Ed.; Scrivener Publishing 2019; pp. 1-47.

6. Cataldo, S.; Salice, P.; Menna, E.; Pignataro, B. Carbon nanotubes and organic solar cells. Energy E Environmental Science 2012, 5, 5919-5940, doi:10.1039/C1EE02276H.

7. Petridis, C.; Kakavelakis, G.; Kymakis, E. Renaissance of graphene-related materials in photovoltaics due to the emergence of metal halide perovskite solar cells. Energy \& Environmental Science 2018, 11, 1030-1061, doi:10.1039/c7ee03620e.

8. Albero, J.; Mateo, D.; Garcia, H. Graphene-Based Materials as Efficient Photocatalysts for Water Splitting. Molecules 2019, 24, 906, doi:10.3390/molecules24050906. 
9. Amollo, T.A.; Mola, G.T.; Nyamori, V.O. Organic solar cells: Materials and prospects of graphene for active and interfacial layers. Critical Reviews in Solid State and Materials Sciences 2020, 45, 261-288, doi:10.1080/10408436.2019.1632791.

10. Das, S.; Pandey, D.; Thomas, J.; Roy, T. The Role of Graphene and Other 2D Materials in Solar Photovoltaics. Advanced Materials 2019, 31, 1802722, doi:10.1002/adma.201802722.

11. Jeon, I.; Matsuo, Y.; Maruyama, S. Single-Walled Carbon Nanotubes in Solar Cells. Topics in Current Chemistry 2018, 376, 4, doi:10.1007/s41061-017-0181-0.

12. Paulo, S.; Palomares, E.; Martinez-Ferrero, E. Graphene and Carbon Quantum Dot-Based Materials in Photovoltaic Devices: From Synthesis to Applications. Nanomaterials 2016, 6, 157, doi:10.3390/nano6090157.

13. Loh, K.P.; Tong, S.W.; Wu, J.S. Graphene and Graphene-like Molecules: Prospects in Solar Cells. Journal of the American Chemical Society 2016, 138, 1095-1102, doi:10.1021/jacs.5b10917.

14. Gatti, T.; Vicentini, N.; Mba, M.; Menna, E. Organic Functionalized Carbon Nanostructures for Functional Polymer-Based Nanocomposites. European Journal of Organic Chemistry 2016, 2016, 1071-1090, doi:10.1002/ejoc.201501411.

15. Wick, P.; Louw-Gaume, A.E.; Kucki, M.; Krug, H.F.; Kostarelos, K.; Fadeel, B.; Dawson, K.A.; Salvati, A.; Vazquez, E.; Ballerini, L.; et al. Classification Framework for Graphene-Based Materials. Angewandte Chemie-International Edition 2014, 53, 7714-7718, doi:10.1002/anie.201403335.

16. Gavrel, G.; Jousselme, B.; Filoramo, A.; Campidelli, S.; Marcaccio, M.; Paolucci, F. Supramolecular Chemistry of Carbon Nanotubes. Making and Exploiting Fullerenes, Graphene, and Carbon Nanotubes 2014, 348, 95-126, doi:10.1007/128_2013_450.

17. Maggini, M.; Scorrano, G.; Prato, M. Addition of azomethine ylides to C-60 - synthesis, characterization, and functionalization of fullerene pyrrolidines. Journal of the American Chemical Society 1993, 115, 9798-9799, doi:10.1021/ja00074a056.

18. Georgakilas, V.; Kordatos, K.; Prato, M.; Guldi, D.M.; Holzinger, M.; Hirsch, A. Organic functionalization of carbon nanotubes. Journal of the American Chemical Society 2002, 124, 760-761, doi:10.1021/ja016954m.

19. Quintana, M.; Spyrou, K.; Grzelczak, M.; Browne, W.R.; Rudolf, P.; Prato, M. Functionalization of Graphene via 1,3-Dipolar Cycloaddition. Acs Nano 2010, 4, 3527-3533, doi:10.1021/nn100883p.

20. Bahr, J.L.; Tour, J.M. Highly functionalized carbon nanotubes using in situ generated diazonium compounds. Chemistry of Materials 2001, 13, 3823-+, doi:10.1021/cm0109903.

21. Salice, P.; Fabris, E.; Sartorio, C.; Fenaroli, D.; Figà, V.; Casaletto, M.P.; Cataldo, S.; Pignataro, B.; Menna, E. An Insight into the Functionalisation of Carbon Nanotubes by Diazonium Chemistry: Towards a Controlled Decoration. Carbon 2014, 74, 73-82, doi:10.1016/j.carbon.2014.02.084.

22. Liu, J.; Rinzler, A.G.; Dai, H.J.; Hafner, J.H.; Bradley, R.K.; Boul, P.J.; Lu, A.; Iverson, T.; Shelimov, K.; Huffman, C.B.; et al. Fullerene pipes. Science 1998, 280, 1253-1256, doi:10.1126/science.280.5367.1253.

23. Perez, E.; Martin, N. pi-pi interactions in carbon nanostructures. Chemical Society Reviews 2015, 44, 6425-6433, doi:10.1039/c5cs00578g.

24. Salice, P.; Gambarin, A.; Daldosso, N.; Mancin, F.; Menna, E. Noncovalent Interaction between Single-Walled Carbon Nanotubes and Pyrene-Functionalized Gold Nanoparticles in Water-Soluble Nanohybrids. The Journal of Physical Chemistry C 2014, 118, 27028-27038, doi:10.1021/jp505005e.

25. Wang, H.; Bi, S.G.; Ye, Y.S.; Xue, Y.; Xie, X.L.; Mai, Y.W. An effective non-covalent grafting approach to functionalize individually dispersed reduced graphene oxide sheets with high grafting density, solubility and electrical conductivity. Nanoscale 2015, 7, 3548-3557, doi:10.1039/c4nr06710j.

26. Ehli, C.; Guldi, D.M.; Herranz, M.A.; Martin, N.; Campidelli, S.; Prato, M. Pyrene-tetrathiafulvalene supramolecular assembly with different types of carbon nanotubes. Journal of Materials Chemistry 2008, 18, 1498-1503, doi:10.1039/b716892f.

27. Samanta, S.K.; Fritsch, M.; Scherf, U.; Gomulya, W.; Bisri, S.Z.; Loi, M.A. Conjugated Polymer-Assisted Dispersion of SingleWall Carbon Nanotubes: The Power of Polymer Wrapping. Accounts of Chemical Research 2014, 47, 2446-2456, doi:10.1021/ar500141j.

28. Gomulya, W.; Gao, J.; Loi, M. Conjugated polymer-wrapped carbon nanotubes: physical properties and device applications. European Physical Journal B 2013, 86, doi:10.1140/epjb/e2013-40707-9.

29. Monteiro, A.R.; Neves, M.; Trindade, T. Functionalization of Graphene Oxide with Porphyrins: Synthetic Routes and Biological Applications. Chempluschem 2020, 85, 1857-1880, doi:10.1002/cplu.202000455.

30. Smith, B.W.; Monthioux, M.; Luzzi, D.E. Encapsulated C-60 in carbon nanotubes. Nature 1998, 396, 323-324, doi:10.1038/24521.

31. Campestrini, S.; Corvaja, C.; De Nardi, M.; Ducati, C.; Franco, L.; Maggini, M.; Meneghetti, M.; Menna, E.; Ruaro, G. Investigation of the Inner Environment of Carbon Nanotubes with a Fullerene-Nitroxide Probe. Small 2008, 4, 350-356, doi:10.1002/smll.200700909.

32. Loi, M.A.; Gao, J.; Cordella, F.; Blondeau, P.; Menna, E.; Bartova, B.; Hebert, C.; Lazar, S.; Botton, G.A.; Milko, M.; et al. Encapsulation of Conjugated Oligomers in Single-Wall Carbon Nanotubes: Towards Nanohybrids for Photonic Devices. Advanced Materials 2010, 22, 1635-1639, doi:10.1002/adma.200903527.

33. D'Este, M.; De Nardi, M.; Menna, E. A co-functionalization approach to soluble and functional Single-Walled Carbon Nanotubes. European Journal of Organic Chemistry 2006, 2006, 2517-2522, doi:10.1002/ejoc.200600196. 
34. Ahmad, A.; Kurkina, T.; Kern, K.; Balasubramanian, K. Applications of the Static Quenching of Rhodamine B by Carbon Nanotubes. Chemphyschem 2009, 10, 2251-2255, doi:10.1002/cphc.200900246.

35. Liu, L.; Wang, T.X.; Li, J.X.; Guo, Z.X.; Dai, L.M.; Zhang, D.Q.; Zhu, D.B. Self-assembly of gold nanoparticles to carbon nanotubes using a thiol-terminated pyrene as interlinker. Chemical Physics Letters 2003, 367, 747-752, doi:10.1016/s00092614(02)01789-x.

36. O'Regan, B.; Grätzel, M. A low-cost, high-efficiency solar cell based on dye-sensitized colloidal TiO2 films. Nature 1991, 353, 737-740, doi:10.1038/353737a0.

37. Hagfeldt, A.; Boschloo, G.; Sun, L.C.; Kloo, L.; Pettersson, H. Dye-Sensitized Solar Cells. Chemical Reviews 2010, 110, 65956663, doi:10.1021/cr900356p.

38. Park, N.G.; Kim, K. Transparent solar cells based on dye-sensitized nanocrystalline semiconductors. Physica Status Solidi aApplications and Materials Science 2008, 205, 1895-1904, doi:10.1002/pssa.200778938.

39. Mishra, A.; Fischer, M.K.R.; Bäuerle, P. Metal-Free Organic Dyes for Dye-Sensitized Solar Cells: From Structure: Property Relationships to Design Rules. Angewandte Chemie International Edition 2009, 48, 2474-2499, doi:https://doi.org/10.1002/anie.200804709.

40. Kim, B.-G.; Chung, K.; Kim, J. Molecular Design Principle of All-organic Dyes for Dye-Sensitized Solar Cells. Chemistry - A European Journal 2013, 19, 5220-5230, doi:https://doi.org/10.1002/chem.201204343.

41. Roy-Mayhew, J.D.; Aksay, I.A. Graphene Materials and Their Use in Dye-Sensitized Solar Cells. Chemical Reviews 2014, 114, 6323-6348, doi:10.1021/cr400412a.

42. Batmunkh, M.; Biggs, M.J.; Shapter, J.G. Carbon Nanotubes for Dye-Sensitized Solar Cells. Small 2015, 11, 2963-2989, doi:https://doi.org/10.1002/smll.201403155.

43. Yan, X.; Cui, X.; Li, B.; Li, L.-s. Large, Solution-Processable Graphene Quantum Dots as Light Absorbers for Photovoltaics. Nano Letters 2010, 10, 1869-1873, doi:10.1021/nl101060h.

44. Mak, K.F.; Sfeir, M.Y.; Wu, Y.; Lui, C.H.; Misewich, J.A.; Heinz, T.F. Measurement of the Optical Conductivity of Graphene. Physical Review Letters 2008, 101, 196405, doi:10.1103/PhysRevLett.101.196405.

45. Gatti, T.; Manfredi, N.; Boldrini, C.; Lamberti, F.; Abbotto, A.; Menna, E. A D- $\pi$-A organic dye - Reduced graphene oxide covalent dyad as a new concept photosensitizer for light harvesting applications. Carbon 2017, 115, 746-753, doi:https://doi.org/10.1016/j.carbon.2017.01.081.

46. Salice, P.; Sartorio, C.; Burlini, A.; Improta, R.; Pignataro, B.; Menna, E. On the trade-off between processability and optoelectronic properties of single wall carbon nanotube derivatives in thin film heterojunctions. Journal of Materials Chemistry $C$ 2015, 3, 303-312, doi:10.1039/c4tc01350f.

47. Guarracino, P.; Gatti, T.; Canever, N.; Abdu-Aguye, M.; Loi, M.A.; Menna, E.; Franco, L. Probing photoinduced electrontransfer in graphene-dye hybrid materials for DSSC. Physical Chemistry Chemical Physics 2017, 19, 27716-27724, doi:10.1039/c7cp04308b.

48. Singh, S.P.; Roy, M.S.; Thomas, K.R.J.; Balaiah, S.; Bhanuprakash, K.; Sharma, G.D. New Triphenylamine-Based Organic Dyes with Different Numbers of Anchoring Groups for Dye-Sensitized Solar Cells. The Journal of Physical Chemistry C 2012, 116, 5941-5950, doi:10.1021/jp210971u.

49. Mphahlele, N.E.; Le Roux, L.; Jafta, C.J.; Cele, L.; Mathe, M.K.; Nyokong, T.; Kobayashi, N.; Ozoemena, K.I. Carbon nanotube-enhanced photoelectrochemical properties of metallo-octacarboxyphthalocyanines. Journal of Materials Science 2014, 49, 340-346, doi:10.1007/s10853-013-7710-1.

50. Jang, S.-R.; Vittal, R.; Kim, K.-J. Incorporation of Functionalized Single-Wall Carbon Nanotubes in Dye-Sensitized TiO2 Solar Cells. Langmuir 2004, 20, 9807-9810, doi:10.1021/la049022f.

51. Volland, M.; Lennert, A.; Roth, A.; Ince, M.; Torres, T.; Guldi, D.M. Azulenocyanines immobilized on graphene; on the way to panchromatic absorption and efficient DSSC blocking layers. Nanoscale 2019, 11, 10709-10715, doi:10.1039/c9nr02300c.

52. Kaur, R.; Kim, K.-H.; Deep, A. A convenient electrolytic assembly of graphene-MOF composite thin film and its photoanodic application. Applied Surface Science 2017, 396, 1303-1309, doi:10.1016/j.apsusc.2016.11.150.

53. So, M.C.; Wiederrecht, G.P.; Mondloch, J.E.; Hupp, J.T.; Farha, O.K. Metal-organic framework materials for light-harvesting and energy transfer. Chemical Communications 2015, 51, 3501-3510, doi:10.1039/c4cc09596k.

54. Lee, C.Y.; Farha, O.K.; Hong, B.J.; Sarjeant, A.A.; Nguyen, S.T.; Hupp, J.T. Light-Harvesting Metal-Organic Frameworks (MOFs): Efficient Strut-to-Strut Energy Transfer in Bodipy and Porphyrin-Based MOFs. Journal of the American Chemical Society 2011, 133, 15858-15861, doi:10.1021/ja206029a.

55. Li, Y.; Tang, J.; He, L.; Liu, Y.; Liu, Y.; Chen, C.; Tang, Z. Core-Shell Upconversion Nanoparticle@Metal-Organic Framework Nanoprobes for Luminescent/Magnetic Dual-Mode Targeted Imaging. Adv Mater 2015, 27, 4075-4080, doi:10.1002/adma.201501779.

56. Lee, D.Y.; Shinde, D.V.; Yoon, S.J.; Cho, K.N.; Lee, W.; Shrestha, N.K.; Han, S.-H. Cu-Based Metal-Organic Frameworks for Photovoltaic Application. The Journal of Physical Chemistry C 2014, 118, 16328-16334, doi:10.1021/jp4079663.

57. Ludin, N.A.; Al-Alwani Mahmoud, A.M.; Bakar Mohamad, A.; Kadhum, A.A.H.; Sopian, K.; Abdul Karim, N.S. Review on the development of natural dye photosensitizer for dye-sensitized solar cells. Renewable and Sustainable Energy Reviews 2014, 31, 386-396, doi:https://doi.org/10.1016/j.rser.2013.12.001. 
58. Calogero, G.; Citro, I.; Di Marco, G.; Armeli Minicante, S.; Morabito, M.; Genovese, G. Brown seaweed pigment as a dye source for photoelectrochemical solar cells. Spectrochimica Acta Part A: Molecular and Biomolecular Spectroscopy 2014, 117, 702706, doi:https://doi.org/10.1016/j.saa.2013.09.019.

59. Enciso, P.; Cerdá, M.F. Solar cells based on the use of photosensitizers obtained from Antarctic red algae. Cold Regions Science and Technology 2016, 126, 51-54, doi:https://doi.org/10.1016/j.coldregions.2016.04.002.

60. Armeli Minicante, S.; Ambrosi, E.; Back, M.; Barichello, J.; Cattaruzza, E.; Gonella, F.; Scantamburlo, E.; Trave, E. Development of an eco-protocol for seaweed chlorophylls extraction and possible applications in dye sensitized solar cells. Journal of Physics D: Applied Physics 2016, 49, 295601, doi:10.1088/0022-3727/49/29/295601.

61. Saedi, A.; Moradi, A.M.; Kimiagar, S.; Panahi, H.A. Efficiency Enhancement of Dye-Sensitized Solar Cells Based on Gracilaria/Ulva Using Graphene Quantum Dot. International Journal of Environmental Research 2020, 14, 393-402, doi:10.1007/s41742-020-00265-2.

Nguyen-Phan, T.-D.; Pham, V.H.; Shin, E.W.; Pham, H.-D.; Kim, S.; Chung, J.S.; Kim, E.J.; Hur, S.H. The role of graphene oxide content on the adsorption-enhanced photocatalysis of titanium dioxide/graphene oxide composites. Chemical Engineering Journal 2011, 170, 226-232, doi:https://doi.org/10.1016/j.cej.2011.03.060.

63. Zhu, Z.; Ma, J.; Wang, Z.; Mu, C.; Fan, Z.; Du, L.; Bai, Y.; Fan, L.; Yan, H.; Phillips, D.L.; et al. Efficiency Enhancement of Perovskite Solar Cells through Fast Electron Extraction: The Role of Graphene Quantum Dots. Journal of the American Chemical Society 2014, 136, 3760-3763, doi:10.1021/ja4132246.

64. Sireesha, P.; Sasikumar, R.; Chen, S.-M.; Su, C.; Ranganathan, P.; Rwei, S.-P. Carboxylic acid-functionalized multi-walled carbon nanotubes-polyindole/Ti2O3: A novel hybrid nanocomposite as highly efficient photo-anode for dye-sensitized solar cells (DSSCs). Applied Surface Science 2017, 423, 147-153, doi:10.1016/j.apsusc.2017.06.131.

65. Xie, L.; Song, W.; Ge, J.; Tang, B.; Zhang, X.; Wu, T.; Ge, Z. Recent progress of organic photovoltaics for indoor energy harvesting. Nano Energy 2021, 82, doi:10.1016/j.nanoen.2021.105770.

66. Wu, X.; Liu, Y.; Qi, F.; Lin, F.; Fu, H.; Jiang, K.; Wu, S.; Bi, L.; Wang, D.; Xu, F.; et al. Improved stability and efficiency of perovskite/organic tandem solar cells with an all-inorganic perovskite layer. Journal of Materials Chemistry A 2021, doi:10.1039/d0ta12286f.

67. Dou, L.; You, J.; Hong, Z.; Xu, Z.; Li, G.; Street, R.; Yang, Y. 25th Anniversary Article: A Decade of Organic/Polymeric Photovoltaic Research. Advanced Materials 2013, 25, 6642-6671, doi:10.1002/adma.201302563.

68. Rafique, S.; Abdullah, S.; Sulaiman, K.; Iwamoto, M. Fundamentals of bulk heterojunction organic solar cells: An overview of stability/degradation issues and strategies for improvement. Renewable E Sustainable Energy Reviews 2018, 84, 43-53, doi:10.1016/j.rser.2017.12.008.

69. Duan, L.; Elumalai, N.; Zhang, Y.; Uddin, A. Progress in non-fullerene acceptor based organic solar cells. Sol Energ Mat Sol C 2019, 193, 22-65, doi:10.1016/j.solmat.2018.12.033.

70. Tonui, P.; Oseni, S.; Sharma, G.; Yan, Q.; Mola, G. Perovskites photovoltaic solar cells: An overview of current status. Renewable \& Sustainable Energy Reviews 2018, 91, 1025-1044, doi:10.1016/j.rser.2018.04.069.

71. Pham, H.; Li, X.; Li, W.; Manzhos, S.; Kyaw, A.; Sonar, P. Organic interfacial materials for perovskite-based optoelectronic devices. Energy \& Environmental Science 2019, 12, 1177-1209, doi:10.1039/c8ee02744g.

72. Carulli, F.; Scavia, G.; Lassi, E.; Pasini, M.; Galeotti, F.; Brovelli, S.; Giovanella, U.; Luzzati, S. A bifunctional conjugated polyelectrolyte for the interfacial engineering of polymer solar cells. Journal of Colloid and Interface Science 2019, 538, 611-619, doi:10.1016/j.jcis.2018.12.027.

73. Lassi, E.; Squeo, B.; Sorrentino, R.; Scavia, G.; Mrakic-Sposta, S.; Gussoni, M.; Vercelli, B.; Galeotti, F.; Pasini, M.; Luzzati, S. Sulfonate-Conjugated Polyelectrolytes as Anode Interfacial Layers in Inverted Organic Solar Cells. Molecules 2021, 26, doi:10.3390/molecules26030763.

74. Cho, H.; Liao, W.; Lin, W.; Yoshimura, M.; Wu, J. Pristine reduced graphene oxide as an energy-matched auxiliary electron acceptor in nanoarchitectural metal oxide/poly(3-hexylthiophene) hybrid solar cell. Journal of Power Sources 2015, 293, 246252, doi:10.1016/j.jpowsour.2015.05.082.

75. Jiao, Y.; Ma, F.; Gao, G.; Wang, H.; Bell, J.; Frauenheim, T.; Du, A. Graphene-covered perovskites: an effective strategy to enhance light absorption and resist moisture degradation. RSC Advances 2015, 5, 82346-82350, doi:10.1039/C5RA14381K.

76. Hu, R.; Chu, L.; Zhang, J.; Li, X.; Huang, W. Carbon materials for enhancing charge transport in the advancements of perovskite solar cells. Journal of Power Sources 2017, 361, 259-275, doi:10.1016/j.jpowsour.2017.06.051.

77. Salice, P.; Sartorio, C.P.; Burlini, A.; Improta, R.; Pignataro, B.; Menna, E. On the trade-off between processability and optoelectronic properties of single wall carbon nanotube derivatives in thin film heterojunctions. Journal of Materials Chemistry $C$ 2015, 3, 303-312, doi:10.1039/c4tc01350f.

78. Bachilo, S.; Strano, M.; Kittrell, C.; Hauge, R.; Smalley, R.; Weisman, R. Structure-assigned optical spectra of single-walled carbon nanotubes. Science 2002, 298, 2361-2366, doi:10.1126/science.1078727.

79. O'Connell, M.; Bachilo, S.; Huffman, C.; Moore, V.; Strano, M.; Haroz, E.; Rialon, K.; Boul, P.; Noon, W.; Kittrell, C.; et al. Band gap fluorescence from individual single-walled carbon nanotubes. Science 2002, 297, 593-596, doi:10.1126/science.1072631.

80. Salice, P.; Maity, P.; Rossi, E.; Carofiglio, T.; Menna, E.; Maggini, M. The continuous-flow cycloaddition of azomethine ylides to carbon nanotubes. Chemical Communications 2011, 47, 9092-9094, doi:10.1039/c1cc13155a. 
81. Gatti, T.; Casaluci, S.; Prato, M.; Salerno, M.; Di Stasio, F.; Ansaldo, A.; Menna, E.; Di Carlo, A.; Bonaccorso, F. Boosting Perovskite Solar Cells Performance and Stability through Doping a Poly-3(hexylthiophene) Hole Transporting Material with Organic Functionalized Carbon Nanostructures. Advanced Functional Materials 2016, 26, 7443-7453, doi:10.1002/adfm.201602803.

82. Gatti, T.; Lamberti, F.; Topolovsek, P.; Abdu-Aguye, M.; Sorrentino, R.; Perino, L.; Salerno, M.; Girardi, L.; Marega, C.; Rizzi, G.; et al. Interfacial Morphology Addresses Performance of Perovskite Solar Cells Based on Composite Hole Transporting Materials of Functionalized Reduced Graphene Oxide and P3HT. Solar Rrl 2018, 2, doi:10.1002/solr.201800013.

83. Habisreutinger, S.N.; Leijtens, T.; Eperon, G.E.; Stranks, S.D.; Nicholas, R.J.; Snaith, H.J. Carbon Nanotube/Polymer Composites as a Highly Stable Hole Collection Layer in Perovskite Solar Cells. Nano Letters 2014, 14, 5561-5568, doi:10.1021/n1501982b.

84. Habisreutinger, S.; Leijtens, T.; Eperon, G.; Stranks, S.; Nicholas, R.; Snaith, H. Enhanced Hole Extraction in Perovskite Solar Cells Through Carbon Nanotubes. Journal of Physical Chemistry Letters 2014, 5, 4207-4212, doi:10.1021/jz5021795.

85. Ihly, R.; Dowgiallo, A.-M.; Yang, M.; Schulz, P.; Stanton, N.J.; Reid, O.G.; Ferguson, A.J.; Zhu, K.; Berry, J.J.; Blackburn, J.L. Efficient charge extraction and slow recombination in organic-inorganic perovskites capped with semiconducting singlewalled carbon nanotubes. Energy \& Environmental Science 2016, 9, 1439-1449, doi:10.1039/c5ee03806e.

86. Jeon, N.J.; Lee, H.G.; Kim, Y.C.; Seo, J.; Noh, J.H.; Lee, J.; Seok, S.I. o-Methoxy Substituents in Spiro-OMeTAD for Efficient Inorganic-Organic Hybrid Perovskite Solar Cells. Journal of the American Chemical Society 2014, 136, 7837-7840, doi:10.1021/ja502824c.

87. Jung, C.; Noh, Y.; Bae, J.; Yu, J.; Hwang, I.; Shin, J.; Shin, K.; Lee, J.; Choi, J.; Na, S. Polyacrylonitrile-grafted reduced graphene oxide hybrid: An all-round and efficient hole-extraction material for organic and inorganic-organic hybrid photovoltaics. Nano Energy 2017, 31, 19-27, doi:10.1016/j.nanoen.2016.11.003.

88. Chen, J.; Yao, B.; Li, C.; Shi, G. An improved Hummers method for eco-friendly synthesis of graphene oxide. Carbon 2013, 64, 225-229, doi:10.1016/j.carbon.2013.07.055.

89. Tung, V.; Allen, M.; Yang, Y.; Kaner, R. High-throughput solution processing of large-scale graphene. Nature Nanotechnology 2009, 4, 25-29, doi:10.1038/nnano.2008.329|10.1038/NNANO.2008.329.

90. Dreyer, D.; Todd, A.; Bielawski, C. Harnessing the chemistry of graphene oxide. Chemical Society Reviews 2014, 43, 5288-5301, doi:10.1039/c4cs00060a.

91. Jung, C.; Park, Y.; Hwang, I.; Go, Y.; Na, S.; Shin, K.; Lee, J.; Choi, J. Eco-friendly and simple radiation-based preparation of graphene and its application to organic solar cells. Journal of Physics D-Applied Physics 2014, 47, doi:10.1088/00223727/47/1/015105.

92. Zhang, B.; Zhang, Y.; Peng, C.; Yu, M.; Li, L.; Deng, B.; Hu, P.; Fan, C.; Li, J.; Huang, Q. Preparation of polymer decorated graphene oxide by gamma-ray induced graft polymerization. Nanoscale 2012, 4, 1742-1748, doi:10.1039/c2nr11724j.

93. Gupta, B.; Kumar, N.; Panda, K.; Melvin, A.; Joshi, S.; Dash, S.; Tyagi, A. Effective Noncovalent Functionalization of Poly(ethylene glycol) to Reduced Graphene Oxide Nanosheets through gamma-Radiolysis for Enhanced Lubrication. Journal of Physical Chemistry C 2016, 120, 2139-2148, doi:10.1021/acs.jpcc.5b08762.

94. Sartorio, C.; Figa, V.; Salice, P.; Gragnato, D.; Cataldo, S.; Scopelliti, M.; Improta, R.; Menna, E.; Pignataro, B. Thiophene pyrenyl derivatives for the supramolecular processability of single-walled carbon nanotubes in thin film heterojunction. Synthetic Metals 2017, 229, 7-15, doi:10.1016/j.synthmet.2017.04.018.

95. Hashima, Y.; Ishikawa, Y.; Raifuku, I.; Inoue, I.; Okamoto, N.; Yamashita, I.; Minami, T.; Uraoka, Y. Easy and green preparation of a graphene- $\mathrm{TiO} 2$ nanohybrid using a supramolecular biomaterial consisting of artificially bifunctionalized proteins and its application for a perovskite solar cell. Nanoscale 2018, 10, 19249-19253, doi:10.1039/c8nr04441d.

96. Inou, I.; Zheng, B.; Watanabe, K.; Ishikawa, Y.; Shiba, K.; Yasueda, H.; Uraoka, Y.; Yamashita, I. A novel bifunctional protein supramolecule for construction of carbon nanotube-titanium hybrid material. Chemical Communications 2011, 47, 1264912651, doi:10.1039/c1cc15221a.

97. Inoue, I.; Yamauchi, H.; Okamoto, N.; Toyoda, K.; Horita, M.; Ishikawa, Y.; Yasueda, H.; Uraoka, Y.; Yamashita, I. Thermostable carbon nanotube-TiO2 nanocompsite as electron highways in dye-sensitized solar cell produced by bio-nano-process. Nanotechnology 2015, 26, doi:10.1088/0957-4484/26/28/285601.

98. Yamashita, I. Biosupramolecules for nano-devices: biomineralization of nanoparticles and their applications. Journal of Materials Chemistry 2008, 18, 3813-3820, doi:10.1039/b810190f.

99. Uenuma, M.; Ban, T.; Okamoto, N.; Zheng, B.; Kakihara, Y.; Horita, M.; Ishikawa, Y.; Yamashita, I.; Uraoka, Y. Memristive nanoparticles formed using a biotemplate. Rsc Advances 2013, 3, 18044-18048, doi:10.1039/c3ra42392a.

100. Haikarainen, T.; Paturi, P.; Linden, J.; Haataja, S.; Meyer-Klaucke, W.; Finne, J.; Papageorgiou, A. Magnetic properties and structural characterization of iron oxide nanoparticles formed by Streptococcus suis Dpr and four mutants. Journal of Biological Inorganic Chemistry 2011, 16, 799-807, doi:10.1007/s00775-011-0781-z.

101. Kobayashi, M.; Kumagai, S.; Zheng, B.; Uraoka, Y.; Douglas, T.; Yamashita, I. A water-soluble carbon nanotube network conjugated by nanoparticles with defined nanometre gaps. Chemical Communications 2011, 47, 3475-3477, doi:10.1039/c0cc05503d.

102. Haikarainen, T.; Papageorgiou, A. Dps-like proteins: structural and functional insights into a versatile protein family. Cellular and Molecular Life Sciences 2010, 67, 341-351, doi:10.1007/s00018-009-0168-2. 
103. Okuda, M.; Suzumoto, Y.; Iwahori, K.; Kang, S.; Uchida, M.; Douglas, T.; Yamashita, I. Bio-templated CdSe nanoparticle synthesis in a cage shaped protein, Listeria-Dps, and their two dimensional ordered array self-assembly. Chemical Communications 2010, 46, 8797-8799, doi:10.1039/c0cc03298k.

104. Suppavorasatit, I.; Cadwallader, K. Effect of Enzymatic Deamidation of Soy Protein by Protein-Glutaminase on the FlavorBinding Properties of the Protein under Aqueous Conditions. Journal of Agricultural and Food Chemistry 2012, 60, 7817-7823, doi:10.1021/jf301719k.

105. Husain, A.; Hasan, W.; Shafie, S.; Hamidon, M.; Pandey, S. A review of transparent solar photovoltaic technologies. Renewable E Sustainable Energy Reviews 2018, 94, 779-791, doi:10.1016/j.rser.2018.06.031.

106. Jung, S.; Kim, H.; Lee, J.; Jeong, G.; Park, J.; Park, H. Bio-Inspired Catecholamine-Derived Surface Modifier for GrapheneBased Organic Solar Cells. Acs Applied Energy Materials 2018, 1, 6463-6468, doi:10.1021/acsaem.8b01396.

107. Hong, S.; Kim, J.; Na, Y.; Park, J.; Kim, S.; Singha, K.; Im, G.; Han, D.; Kim, W.; Lee, H. Poly(norepinephrine): Ultrasmooth Material-Independent Surface Chemistry and Nanodepot for Nitric Oxide. Angewandte Chemie-International Edition 2013, 52, 9187-9191, doi:10.1002/anie.201301646.

108. Lee, H.; Dellatore, S.; Miller, W.; Messersmith, P. Mussel-inspired surface chemistry for multifunctional coatings. Science 2007, 318, 426-430, doi:10.1126/science.1147241.

109. Hong, S.; Yeom, J.; Song, I.; Kang, S.; Lee, H. Pyrogallol 2-Aminoethane: A Plant Flavonoid-Inspired Molecule for MaterialIndependent Surface Chemistry. Advanced Materials Interfaces 2014, 1, doi:10.1002/admi.201400113.

110. Yao, T.T.; An, X.R.; Han, H.X.; Chen, J.Q.; Li, C. Photoelectrocatalytic Materials for Solar Water Splitting. Advanced Energy Materials 2018, 8, 1800210, doi:10.1002/aenm.201800210.

111. Ragoussi, M.E.; Malig, J.; Katsukis, G.; Butz, B.; Spiecker, E.; de la Torre, G.; Torres, T.; Guldi, D.M. Linking Photo- and Redoxactive Phthalocyanines Covalently to Graphene. Angewandte Chemie-International Edition 2012, 51, 6421-6425, doi:10.1002/anie.201201452.

112. Li, X.; Li, K.Z.; Wang, D.D.; Huang, J.; Zhang, C.Y.; Du, Y.K.; Yang, P. One-pot synthesis of manganese porphyrin covalently functionalized graphene oxide for enhanced photocatalytic hydrogen evolution. Journal of Porphyrins and Phthalocyanines 2017, 21, 179-188, doi:10.1142/s1088424616501236.

113. Xu, Y.F.; Liu, Z.B.; Zhang, X.L.; Wang, Y.; Tian, J.G.; Huang, Y.; Ma, Y.F.; Zhang, X.Y.; Chen, Y.S. A Graphene Hybrid Material Covalently Functionalized with Porphyrin: Synthesis and Optical Limiting Property. Advanced Materials 2009, 21, 1275-+, doi:10.1002/adma.200801617.

114. Li, R.X.; Liu, X.F.; Liu, T.; Yin, Y.B.; Zhou, Y.; Mei, S.K.; Yan, J. Electrocatalytic properties of FeFe -hydrogenases models and visible-light-driven hydrogen evolution efficiency promotion with porphyrin functionalized graphene nanocomposite. Electrochimica Acta 2017, 237, 207-216, doi:10.1016/j.electacta.2017.03.216.

115. Kowalska, A.M.; Trzaskowski, B.; Osella, S. Assessing the Charge Transfer at the Cytochrome c(553)/Graphene Interface: A Multiscale Investigation. Journal of Physical Chemistry C 2018, 122, 29405-29413, doi:10.1021/acs.jpcc.8b10517.

116. Du, Y.L.; Dong, N.N.; Zhang, M.H.; Zhu, K.; Na, R.Q.; Zhang, S.L.; Sun, N.W.; Wang, G.B.; Wang, J. Covalent functionalization of graphene oxide with porphyrin and porphyrin incorporated polymers for optical limiting. Physical Chemistry Chemical Physics 2017, 19, 2252-2260, doi:10.1039/c6cp05920a.

117. Guldi, D.M.; Taieb, H.; Rahman, G.M.A.; Tagmatarchis, N.; Prato, M. Novel photoactive single-walled carbon nanotubeporphyrin polymer wraps: Efficient and long-lived intracomplex charge separation. Advanced Materials 2005, 17, 871-+, doi:10.1002/adma.200400641.

118. Wang, D.D.; Huang, J.; Li, X.; Yang, P.; Du, Y.K.; Goh, C.M.; Lu, C. Photocatalytic H-2 production under visible-light irradiation based on covalent attachment of manganese phthalocyanine to graphene. Journal of Materials Chemistry A 2015, 3, 4195-4202, doi:10.1039/c4ta05721j.

119. Lewandowska, K.; Rosiak, N.; Bogucki, A.; Cielecka-Piontek, J.; Mizera, M.; Bednarski, W.; Suchecki, M.; Szacilowski, K. Supramolecular Complexes of Graphene Oxide with Porphyrins: An Interplay between Electronic and Magnetic Properties. Molecules 2019, 24, 688, doi:10.3390/molecules24040688.

120. Shen, H.; Wang, Y.-Z.; Liu, G.; Li, L.; Xia, R.; Luo, B.; Wang, J.; Suo, D.; Shi, W.; Yong, Y.-C. A Whole-Cell Inorganic-Biohybrid System Integrated by Reduced Graphene Oxide for Boosting Solar Hydrogen Production. ACS Catalysis 2020, 10, 1329013295, doi:10.1021/acscatal.0c03594.

121. Takaguchi, Y.; Sako, Y.; Yanagimoto, Y.; Tsuboi, S.; Motoyoshiya, J.; Aoyama, H.; Wakahara, T.; Akasaka, T. Facile and reversible synthesis of an acidic water-soluble poly(amidoamine) fullerodendrimer. Tetrahedron Letters 2003, 44, 5777-5780, doi:https://doi.org/10.1016/S0040-4039(03)01425-4.

122. Murakami, N.; Miyake, H.; Tajima, T.; Nishikawa, K.; Hirayama, R.; Takaguchi, Y. Enhanced Photosensitized Hydrogen Production by Encapsulation of Ferrocenyl Dyes into Single-Walled Carbon Nanotubes. Journal of the American Chemical Society 2018, 140, 3821-3824, doi:10.1021/jacs.7b12845.

123. Tajima, T.; Yamagami, M.; Sagawa, R.; Miyake, H.; Takaguchi, Y. Dye-sensitized H-2 evolution from water facilitated by photoinduced electron transfer between molecules on the inside and the outside of a carbon nanotube. Journal of Applied Physics 2021, 129, doi:10.1063/5.0026896. 
124. Zeng, L.; Li, X.; Fan, S.; Yin, Z.; Mu, J.; Qin, M.; Chen, A. Solar-driven bio-electro-chemical system for synergistic hydrogen evolution and pollutant elimination simultaneously over defect-rich CoN-MoS2/biomass nanosheets. Journal of Power Sources 2020, 478, 228755, doi:10.1016/j.jpowsour.2020.228755. 